
\title{
25 Research Square \\ Oceanic Drivers and Empirical Prediction of Interannual Rainfall Variability in Late Summer Over Northeast China
}

\author{
Junhu Zhao
}

National Climate Center https://orcid.org/0000-0002-8304-6244

Han Zhang

Lanzhou University

Jinqing Zuo

National Climate Center

Liu Yang

Lanzhou University

Jie Yang

Jiangsu Climate Center

Kaiguo Xiong

Wuhan Regional Climate Center

Guolin Feng ( $\nabla$ fenggl@cma.gov.cn )

National Climate Center

Wenjie Dong

Sun Yat-Sen University

\section{Research Article}

Keywords: Northeast China monsoon rainfall, Interannual variability, Oceanic drivers, Empirical prediction model

Posted Date: July 12th, 2021

DOl: https://doi.org/10.21203/rs.3.rs-680517/v1

License: (c) (i) This work is licensed under a Creative Commons Attribution 4.0 International License. Read Full License

Version of Record: A version of this preprint was published at Climate Dynamics on August 26th, 2021. See the published version at https://doi.org/10.1007/s00382-021-05945-z. 


\section{Abstract}

Northeast China (NEC) is located between the subtropical monsoon and temperate-frigid monsoon regions and exhibits two successive rainy seasons with different natures: the northeast cold vortex rainy season in early summer (May-June) and the monsoon rainy season in late summer (July-August). Summer rainfall over NEC (NECR) has a fundamental influence on society, yet its successful seasonal prediction remains a long-term scientific challenge to current dynamical models. The poor NECR prediction skill is partly attributed to the large NECR variability at both the interannual and interdecadal time scales. Here, we focus on the oceanic drivers of the late summer NECR variability and associated physical processes at interannual time scale. Then, we establish an empirical prediction model to predict the interannual variability of summer NECR at one-month lead time (in June). The analysis of observations spanning 40 years (1963-2002) reveals three physically and synergistically influencing predictors of the late summer NECR interannual variability. Above-normal NECR is preceded in the previous spring by (a) warm sea surface temperature (SST) anomalies in the tropical northern Indian Ocean, (b) a positive thermal contrast tendency in the tropical West-East Pacific SST, and (c) a positive tendency of the North Atlantic tripolar SST. These precursors enhance the anomalous low-level anticyclone over the Northwest Pacific and southerly anomalies over NEC in late summer, which are beneficial to enhancing NECR. An empirical prediction model built on these three predictors achieves a forecast temporal correlation coefficient (TCC) skill of 0.72 for 1961-2019, and a 17-year (2003-2019) independent forecast shows a significant TCC skill of 0.70 . The skill is substantially higher than that of five state-of-the-art dynamical models and their ensemble mean for 1979-2019 (TCC=0.24). These results suggest that the proposed empirical model is a very meaningful approach for the prediction of NECR, although the dynamical prediction of NECR has considerable room for improvement.

\section{Introduction}

Northeast China (NEC), located in the mid-high latitudes of East Asia on the northern edge of the East Asian summer monsoon (EASM) region, is a major food-producing region and constitutes one of China's industrial bases. Because of this geographical relationship, the precipitation variability in NEC is influenced by the EASM (e.g., Li and Zeng 2002; Lian et al. 2003; Wu and Li 2008; Li et al. 2010; Sun et al. 2017) and mid-high-latitude westerly circulation systems (Hu et al. 2010; Fang et al. 2018). The integrated effects of the monsoonal climate and terrain result in a unique NEC rainfall (NECR) pattern (Gao et al. 2014a, 2014b; Han et al. 2015). NECR is concentrated mainly in summer, and accurately predicting summer NECR is of utmost importance for agricultural and industrial production planning, water resource management, etc (Huang et al. 1993). Unfortunately, despite the rapid development of dynamical climate models in recent decades, the state-of-the-art seasonal forecast models still have limited skill in predicting summer rainfall variability over East Asia (Wang et al. 2009). Remarkably, both real-time forecasts and dynamical model forecasts of summer NECR have shown the poorest skills, especially in recent years (Zhao et al. 2020). 
Zhao et al. (2020) emphasized several difficulties regarding the prediction of summer NECR. First, the EASM rain belt generally migrates northward from South China in May to North China in July and reaches NEC in middle July (Lian et al. 2003), leading to two successive rainy seasons in NEC with different natures: the northeast cold vortex rainy season in early summer (May-June, $\mathrm{MJ}$ ) and the monsoon rainy season in late summer (July-August, JA). The characteristics of the atmospheric circulation anomalies associated with NECR are distinctly different between MJ and JA. In MJ, before the arrival of the EASM, NECR is dominated mainly by westerly circulation systems such as the NEC cold vortex (He et al. 2007; Hu et al. 2010; Shen et al. 2011; Fang et al. 2018); in contrast, during JA, NECR is primarily dominated by the EASM, such as the EASM or NEC southerly wind (Sun et al. 2003, 2017), the western North Pacific subtropical high (Shen et al. 2011; Xiang et al. 2013; Zhao et al. 2018), and northward-moving typhoons (Chen and Zhang 2020). Due to the different systems that influence the NECR variability between MJ and $\mathrm{JA}$, it is difficult to skillfully forecast the total summer rainfall covering both the MJ and JA seasons. JA rainfall accounts for approximately $80 \%$ of the total summer rainfall over NEC. Secondly, summer NECR exhibits obviously distinct variability at interannual and interdecadal time scales (Sun et al. 2000; Gao et al. 2014a; Han et al. 2015). Sun et al. (2000) reported obvious 2-4-, 11-, 22-, and 34-year variation cycles of summer NECR during 1909-1997. The summer NECR decreased from the early 1970s to the early 1980s and then began to increase until the end of the 20th century (Gao et al. 2014a). Subsequently, a positive shift to less NECR occurred during 1999-2012 compared with 1984-1998 (Han et al. 2015). The interannual and interdecadal variability of NECR is remarkably different between MJ and JA (Zhao et al. 2018). Therefore, it may be beneficial to predict NECR separately during MJ and JA, at interannual and interdecadal time scales.

Thus, different from traditional JJA-averaged forecasts, this study focuses on the interannual variability and seasonal prediction of JA-averaged NECR. This season involves the arrival of the EASM in NEC and the onset of the monsoon rainy season over NEC and the Korean Peninsula. Note that the westerly rainfall belt and the strong EASM rainfall belt converge over NEC (Fig. 1a), which is the center of mean JA precipitation and exhibits the largest interannual variability at middle-high latitudes (Fig. 1b). Locally, JA is the peak rainy season with the largest standard deviation over NEC (Fig. 1c). Nevertheless, compared with other parts of China, the seasonal precipitation prediction skill is relatively low in NEC (Zhao et al. 2020); as shown in Fig. 1d, the temporal correlation coefficient (TCC) between observed and forecasted NEC precipitation obtained by the multimodel ensemble (MME) mean of 5 state-of-the-art models issued in June is only 0.24 . This indicates that an in-depth analysis is urgently needed to satisfy the growing requirements of and demands for forecast information related to seasonal monsoon rainfall in NEC. For these reasons, the present study focuses on the interannual variability of NECR in JA. Because seasonal dynamic models are powerless for predicting the interannual variability of East Asian monsoon rainfall, many studies have built physical-empirical models based on several well-chosen external forcing predictors, El Niño-Southern Oscillation (ENSO), the Indian Ocean sea surface temperature (SST), and the North Atlantic SST (Wu et al. 2009; Guo et al. 2012; Wang et al. 2013; Yim et al. 2014; Wu and Yu 2016; Wen et al. 2017). In brief, this study aims to identify the oceanic drivers of interannual NECR variability in JA and examine the associated physical mechanism for the linkages. Also, we seek to 
establish an empirical prediction model based on oceanic drivers to better understand the origins of the interannual NECR variability in JA.

The remainder of this paper is organized as follows. Section 2 introduces the datasets and methods used in this study. Section 3 describes the atmospheric circulation anomalies associated with the interannual NECR variability in JA. In Section 4, the oceanic predictors are ascertained, and their associations with NECR are explored by both observation analysis and numerical modeling experiments. Section 5 presents the empirical prediction model of the interannual NECR variability in JA. The main results and discussion are given in Section 6 .

\section{Data, Model, And Experiments}

\subsection{Observational data and method}

The observed precipitation data are derived from the China Precipitation Daily Data Set V3.0 provided by the Chinese Meteorological Information Center. This dataset contains precipitation from 2374 meteorological stations that have undergone strict quality control procedures. To measure the variation in monsoon rainfall, we selected 247 stations over the NEC region $\left(38-53^{\circ} \mathrm{N}, 115-135^{\circ} \mathrm{E}\right)(\mathrm{Fig} .1 \mathrm{~b})$ and constructed a JA NEC rainfall index (NECRI) averaged over those 247 stations (called Stn-NECRI). For comparison, the National Oceanic and Atmospheric Administration's (NOAA's) Precipitation Reconstruction (PREC) dataset (Chen et al. 2002) is also used. Precipitation data from PREC were interpolated into 247 stations over NEC using bilinear interpolation (called PREC-NECRI). The JA StnNECRI shows high consistency (correlation coefficient, Corr=0.97) with the PREC-NECRI, as shown in Fig. 1d. The atmospheric reanalysis data are obtained from the National Centers for Environmental Prediction/National Center for Atmospheric Research (NCEP/NCAR) (Kalnay et al. 1996) over the period of 1948-2019, and the SST data are obtained from the Met Office Hadley Centre Sea Ice and Sea Surface Temperature (HadISST) dataset (Reynolds et al. 2002) over the period of 1870-2019.

To verify the forecast capability of the empirical model, five state-of-the-art coupled seasonal forecast models are employed, namely, the Beijing Climate Center Climate System Model (BCC-CSM1.1) (Wu et al. 2013), NCEP Climate Forecast System (CFS) version 2 (CFSv2) (Saha et al. 2014), European Centre for Medium-Range Weather Forecasts System 4 (ECMWFv4) (Kim et al. 2012), Global Seasonal Forecast System version 5 (GloSea5) (MacLachlan et al. 2015), and Japan Meteorological Agency/Meteorological Research Institute-Coupled Prediction System version 2 (JMA/MRI-CPS2) (Takaya et al. 2018), which are adopted from the Asia-Pacific Economic Cooperation Climate Center (APCC)/Climate Prediction and its Application to Society (CliPAS) project. For comparison with the empirical forecast, retrospective forecasts issued in May and June are used for the period of 2003-2019 targeting the seasonal JA prediction with a 2-month and 1-month lead.

Zhao et al. (2019) investigated the apparent and stable positive correlation between JA NECR and the tropical and northern Indian Ocean (TNIO) SST starting in 1963. Therefore, the research period of this 
paper is 1963-2019. To focus on the interannual variability, Fourier decomposition filtering (Forbes. 1988 ) is applied to extract interannual component (variation less than 9 years) of the precipitation, SST and atmospheric circulation during 1961-2019.

Multiple regression method is used to establish the empirical prediction models (Michaelsen. 1987; Li and Wang, 2018). (1) Leave-four-out cross-validated reforecast (Blockeel and Struyf, 2003). To alleviate the over-fitting problem, 4 years centered on a target year are withheld from the training sample, and the regression model is built to forecast the target year. Then, the process is repeated for all the other years to get the cross-validated reforecast for 1963-2002. (2) Independent forecast. The multiple regression model is built with the training data for 1963-2002, and independent forecast is then made for the rest 17-year during 2003-2019. TCC and the Mean Square Skill Score (MSSS) are used to measure the deterministic seasonal forecast skill (WMO, 2002). The MSSS indicates the percentage reduction in mean square error of the model forecast compared to the climatology "forecast". Positive (negative) skill means that the model's forecast is better (poorer) than the climatology "forecast". The closer the MSSS value is to 1 , the more accurate the model prediction is.

\subsection{Model and experimental setup}

The atmospheric general circulation model used in this study is the Community Atmospheric Model version 5.3 (CAM5.3) developed by NCAR (Hurrell et al. 2013). The CAM5.3 model can effectively capture the key features of the major seasonal variation of the Asian monsoon rainfall ( $\mathrm{Li}$ and Wang 2015). CAM5.3 is coupled to the Community Land Model, and a version with $1.9^{\circ} \times 2.5^{\circ}$ resolution and 30 vertical levels is used in this study. Three sensitivity experiments are conducted to assess the contribution of SST anomalies (SSTAs) in the tropical West-East Pacific (WEP run), the tropical Indian Ocean (TNIO run) and the Northern Atlantic Ocean (NAT run), respectively. Each sensitivity experiment consists of 50 ensemble members integrated from February to August with slightly varying atmospheric initial conditions from the control run, and the ensemble mean of the 50 members is used for analysis. In the control run, the model is forced with a prescribed monthly climatological mean SST and sea ice that is obtained from the monthly HadISST dataset for the period 1981-2010. A 10-year spin-up is run before conducting the control run. More details about the sensitivity experiments carried out in this study are provided in Section 4.

\section{Simultaneous Sstas And Atmospheric Circulation Anomalies Associated With The Interannual Variation Of Late Summer Necr}

What physical processes dominate the interannual variation of late summer NECR? To figure this out, we first analyze the simultaneous large-scale lower boundary anomalies associated with the interannual variability of late summer NECR. 
It is clear that prominent warm SSTAs are observed over the Indian Ocean, western equatorial Pacific and northwest Pacific, and cold SSTAs over the eastern equatorial Pacific and Northeast Pacific when the NECRI is in its high index phase (Fig. 2a). Besides, there are tripolar-like SSTAs over the North Atlantic Ocean, with warm SSTAs in the North tropical Atlantic and Northwest Atlantic and cold SSTAs in the subtropical Atlantic (Fig. 2a). Correspondingly, enhanced easterly anomalies are observed over the tropical western Pacific and Indian Ocean. These easterly anomalies enhanced a large-scale anomalous anticyclone over the western North Pacific (WNPAC, Fig. 2b), with remarkable southwesterly anomalies and more water vapor on the northwestern flank of WNPAC prevailing from the South China Sea to the southern NEC, resulting in increased interannual NECR (Fig. 2c).

In addition, an equally significant anomalous cyclonic circulation is seen between eastern Mongolia and NEC (Fig. 2b), strengthening local convergence, and leading to a positive NECR anomaly. This anomalous cyclonic circulation (sometimes it might be NEC cold vortex) is possibly related to the tripolar-like SST anomalies over the North Atlantic Ocean, which gives rise to a set of wave trains propagating from the North Atlantic downward to Eurasian mid-high latitudes (Wu et al. 2009; Zuo et al. 2013).

These results are consistent with that of previous studies, which have proposed that NECR is affected mainly by the East Asian subtropical monsoon system (for example, the WNPAC and NEC southerly winds), and the westerly circulation system (such as the NEC cold vortex) in late summer (Fang et al. 2018; Shen et al. 2011; Zhao et al. 2018). Among them, the WNPAC is the dominant factor contributing to the NECR variability by modulating the northward transport of water vapor from the ocean. Air-sea interactions in the Indo-Pacific warm pool and tropical North Atlantic play a key role in affecting NECR by modifying the location and strength of the WNPAC.

\section{Oceanic Drivers Of Late Summer Necr}

Rather than fishing statistical predictors in a variety of oceanic and atmospheric fields, we examine only SSTAs since they are the dominated lower boundary forcing conditions. Following Li and Wang (2018), we focus on two types of precursors, i.e., seasonal mean SSTAs in spring and SST tendency defined as the difference in SSTAs between spring and winter (the former minus the latter). To determine the most meaningful predictors for JA NECR, we calculate correlation coefficients between the SSTs and JA NECRI. Particular attention is paid to the regions where the correlations are significant at the $95 \%$ confidence level.

\subsection{SST predictors}

To explore potential precursors of JA NECR, we investigate correlations of the NECRI with the SSTAs in the preceding winter (December-January-February, DJF) and spring (March-April-May, MAM), and the SST tendency between MAM and DJF. To establish an empirical prediction model, the entire period of $1963-2019\left(\mathrm{~N}=57\right.$ years) was separated into a calibration period of $1963-2002\left(\mathrm{n}_{1}=40\right)$ and an 
independent validation period of 2003-2019 ( $\mathrm{n}_{2}=17$ years). Fig. 3 shows the correlation maps between the JA NECRI and the SSTs in DJF and MAM during 1963-2002. Three empirical predictors with definite physical bases are discovered.

In DJF, there are significant positive correlation coefficients (CCs) in the TNIO, South China Sea, western part of the Maritime Continent, and negative CCs in the tropical central-Eastern Pacific Ocean (Fig. 3a). In the following MAM, enhanced positive CCs remain over the TNIO, while the prominent positive CCs in the tropical central-Eastern Pacific Ocean disappear (Fig. 3b). Thus, we extracted the first predictor index; that is, the MAM TNIO index (TNIOI, SST averaged over $\left.0-15^{\circ} \mathrm{N}, 50-120^{\circ} \mathrm{E}\right)$, which has a significant CC of 0.63 with the JA NECRI. Moreover, the positive relationship between the MAM TNIOI and the JA NECRI is best represented when the values of the NECRI and TNIOI are both greater than 0.5 standard deviation (Fig. 4). For the 40-year calibration period of interest, a high (low) TNIOI in MAM corresponds to 7 (6) extreme positive (negative) NECRI, while the opposite example is only one in JA (Fig. 4a). This finding suggests that the MAM TNIO SSTAs in MAM contribute importantly to the interannual variations of the JA NECR.

Previous studies have revealed that SST tendency can be considered as an important predictor of shortterm climate (Wang et al. 2013; Yim et al. 2014, 2015; Wen et al. 2017). Two additional tendency predictors are selected for the NECRI. The first tendency is a long-term dipolar-like SST tendency with warming in the West Pacific and cooling in the tropical central-Eastern Pacific Ocean from DJF to MAM (Fig. 3c). Therefore, based on Fig. 3c, an index that represents this dipolar-like SST tendency is defined as WEPDT index (WEPDTI, Table 1), which has a significant CC of 0.70 with the JA NECRI (Table 1). For the 40-year calibration period of interest, a high (low) WEPDTI corresponds to 8 (7) extreme wet (dry) JA NECR, while there are no years in which the opposite is true (Fig. 4b). This finding shows that the dipolarlike SST tendency between the Western and Eastern Pacific also contribute to the interannual variations of JA NECR.

The second tendency predictor is the tripolar SSTA over the North Atlantic Ocean from DJF to MAM (Fig. $3 \mathrm{c})$. This tripolar-like pattern is accompanied with warming tendencies in the North tropical Atlantic $\left(0^{\circ}-\right.$ $\left.20^{\circ} \mathrm{N}\right)$ and Northeast Atlantic $\left(46^{\circ}-60^{\circ} \mathrm{N}\right)$ and cooling tendencies in the subtropical Atlantic $\left(26^{\circ}-34^{\circ} \mathrm{N}\right)$. Therefore, based on Fig. 3c, an index reflecting this tripolar SST tendency is defined as NAT index (NATI, Table 1), which has a significant CC of 0.53 with the JA NECRI. For the 40-year calibration period of interest, a high (low) NATI corresponds to 7 (7) extreme wet (dry) JA NECR, while the opposite example is only one year (Fig. 4c).

\subsection{Discussion of physical linkage between the predictors and JA NECR}

For the empirical prediction, it is vital to comprehend the sources of predictability, i.e., the physical processes and mechanisms linking the predictors and predictand. In this section, we give a brief 
discussion of their physical linkage to the interannual variations of JA NECR by both observation analysis and numerical modeling experiments.

\subsubsection{Spring TNIO SST and NECR}

To illustrate the influence of TNIO on JA NECR, regressions of the SST anomalies, stream function and horizontal wind anomalies at $850 \mathrm{hPa}$, and precipitation anomalies in JA against the MAM TNIO index are computed for the period of 1963-2002. It is clear that the TNIO SSTAs strongly persist from MAM to JJA, and the warm SSTAs can spread eastward to the eastern Philippine Sea (Fig. 5a). These warm SSTAs give rise to easterly anomalies over the eastern Indian Ocean-western Pacific (Fig. 5b) via the GillMatsuno mechanism (Gill 1980), which further result in an anomalous anticyclone over the Philippine Sea (i.e., WNPAC). The associated southwesterly anomalies along the northwestern flank of the WNPAC transport more warm moisture into NEC, leading to strengthened rainfall over NEC (Fig. 5c). This is consistent with Wu et al. (2010), which revealed that the TNIO warming plays a dominant role in modulating the WNPAC variability in late summer.

To confirm the possible mechanisms and assess the contribution of TNIO SSTAs to the JA NECR variability, we perform a set of numerical experiments using the CAM5.3 model forced with SSTAs plus the climatological mean SST in the tropical Indian Ocean $\left(30^{\circ} \mathrm{S}-30^{\circ} \mathrm{N}, 30^{\circ}-110^{\circ} \mathrm{E}\right.$; referred to at the TNIO run). Here, the SSTA forcing is derived by regressing the monthly SST anomalies against the MAM TNIOI during 1963-2002. The atmospheric circulation response to the TNIO SSTA forcing is represented as the ensemble-mean difference between the TNIO and control runs (former minus latter).

Figure 6 shows the responses of horizontal wind and stream function at $850 \mathrm{hPa}$, precipitation to the TNIO SSTA forcing in JA. There are positive precipitation responses in most parts of the TNIO (Fig. 6b), indicating that the warm SSTAs in the TNIO tend to enhance the local convection activity. Significant easterly anomalies prevail over the northern tropical Indian Ocean-Western Pacific as a Gill-Matsunotype response, leading to anti-cyclonic flows to the north of the easterly (Fig. 6a). In particular, a strong anti-cyclonic response occurs over the Philippine Sea (Fig. 6a), consistent with its observed counterpart (Fig. 5b). The southwesterly anomalies at the western flank of the anomalous anticyclone favor more water vapor from the ocean to NEC, resulting in enhanced precipitation over there (Fig. 6b), though the amplitude of the simulated precipitation anomalies is weaker than that of the observations. Nevertheless, similarity between the model simulations and observations confirms that the TNIO warming can exert a significant impact on the NEC precipitation variability through enhancing the WNPAC in late summer. Also, our result is supported by the previous studies that TNIO warming can intensify the WNPAC through the eastward propagation of Kelvin waves and/or modulating the Hadley circulation (Sui et al. 2007; Yang et al. 2007; Wu and Zhou 2008; Xie et al. 2009; Wang et al. 2013). It should be noted that the TNIO warming tends to be lagged the El Niño events by one season, and therefore the spring TNIO warming plays a role in linking the previous winter ENSO and following summer weather and climate over East 
Asia (Xie et al. 2009). In addition to ENSO, ocean dynamics and local ocean-atmosphere interaction also contribute to the TNIO SST variability (Huang and Kinter 2002; Du et al. 2009).

\subsubsection{SST tendency index 1-WEPDTI and NECR}

Same as the TNIO index, regressions of large-scale lower boundary anomalies in JA against the WEPDTI are computed to examine influence of the dipolar-like SST tendency in the Pacific Ocean from DJF to MAM. It is indicated that the warming SSTA tendency in the Western Pacific and the cooling SSTA tendency in the tropical Eastern Pacific associated with the WEPDTI can endure until summer (Fig. 7a), which corresponds to the developing phase of La Niña. This east-west dipole SST tendency can strengthen the equatorial easterly anomalies through zonal thermal gradients, thus leading to centraleastern Pacific cooling in the following JA season (Fig. 7a). Such central-eastern Pacific cooling generates westward propagating descending Rossby waves through suppressed convection over the western North Pacific (Li and Wang 2015). This Rossby wave response enhances the WNPAC, resulting in stronger southwesterlies that transport water vapor further north (Fig. 7b), thereby enhancing NECR (Fig. 7c).

To confirm the influence of tropical Pacific SSTAs to the JA NECR variability, we perform another set of numerical experiments using the CAM5.3 model forced with SSTAs plus the climatological mean SST in the tropical Pacific Ocean $\left(20 \mathrm{~S}^{\circ}-20^{\circ} \mathrm{N}, 110^{\circ}-270^{\circ} \mathrm{E}\right.$; referred to at the WEP run). The SSTA forcing is derived by regressing the monthly SST anomalies against the WEPDTI during 1963-2002. Figure 8 shows the differences in the precipitation, horizontal wind and stream function at $850 \mathrm{hPa}$ in response to the tropical Pacific SSTAs forcing in JA. It is indicated that the atmospheric circulation responses are strong in the tropics in the WEP run. Especially, there is a pair of anomalous low-level cyclones over the eastern Pacific-Atlantic region and a pair of anomalous low-level anti-cyclones over the western Pacific (Fig. 8a), and therefore leads to more precipitation anomalies over NEC (Fig. 8b), which are consistent with the results obtained from observations (Fig. 7b). Therefore, the model simulations support the significant influence of the WEPDTI-related SSTAs on the WNPAC and thus the NEC precipitation variability in late summer

\subsubsection{SST tendency index 2-NATI and NECR}

Figure 9 displays regressions of SST and atmospheric circulation anomalies in JA against the NATI. It is shown that the North Atlantic tripolar-like SST tendency, particularly the warming SST tendency in the tropical North Atlantic $\left(0-20^{\circ} \mathrm{N}\right)$, can persist from spring into late summer (Fig. 9a). The delayed impact of Atlantic SSTAs on JA NECR is possibly related to the long persistence of SSTAs from spring to summer (Hong et al. 2014; Zuo et al. 2019) and atmosphere-ocean interactions along the Pacific Intertropical Convergence Zone (Ham et al. 2013). Associated with the high-index phase of the NATI, there is a prominent anomalous anticyclone over the subtropical western North Pacific and a cyclone over the eastern North Pacific-Atlantic (Fig. 9b). Previous studies have suggested that the 
North Atlantic-WNPAC connection is related to an anomalous zonally overturning circulation extending westward from the tropical Atlantic to the tropical Pacific (Hong et al. 2014, 2015; Zuo et al. 2019). When the tropical Atlantic SSTAs are warmer than normal, enhanced local convection activity (Fig. 9d), low-level convergence and upper-level divergence (Fig. 9c) are clearly observed over the heating forcing.

Consequently, enhanced upper-level convergence and low-level divergence are observed over the central tropical Pacific, which suppress the local convection activity and in turn trigger an anomalous low-level anticyclone over the western North Pacific as a Rossby-wave response. Moreover, an anomalous cyclone is observed over Northeast China (Fig. 9b). This anomalous cyclone over Northeast China and the enhanced WNPAC favor intensified NECR in JA (Fig. 9d).

To confirm the linkage between the NAT and JA NECR, numerical experiments are conducted with the CAM5.3 model forced with SSTAs plus the climatological mean SST in the North Atlantic Ocean $\left(0^{\circ}-\right.$ $70^{\circ} \mathrm{N}, 10^{\circ}-70^{\circ} \mathrm{W}$; referred to at the NAT run). Here, the SSTA forcing is derived by regressing the monthly SST anomalies against the NATI during 1963-2002. Figure 10 shows the ensemble-mean differences of the $850-\mathrm{hPa}$ stream function and horizontal wind, 200-hPa velocity potential, and precipitation in JA between the NAT run and control run (former minus latter). It is indicated that the atmospheric circulation and precipitation in JA responses to the NAT SST forcing are strong, which are highly consistent with the observations. Particularly, there are apparent positive precipitation responses over the tropical North Atlantic (Fig. 10c), indicating that the warm SSTAs over there tend to enhance local convection activity. Correspondingly, a pair of anomalous low-level cyclonic flow responses occurs over the subtropical eastern Pacific-western Atlantic, and a pair of anomalous low-level anticyclone occurs over the western North Pacific in the experiments (Fig. 10a), the pattern of which is similar to its observed counterpart (Fig. 9b).

Moreover, there is significant anomalous low-level convergence and upper-level divergence over the tropical North Atlantic and opposite anomalies over the central tropical Pacific in the high-index phase of the NATI (Fig. 10b). Therefore, the tropical North Atlantic warming appears to be accompanied by an anomalous zonally overturning circulation extending westward from the tropical Atlantic to the central tropical Pacific in JA, which is associated with anomalous ascending motion over the tropical North Atlantic and opposite anomalies over the central tropical Pacific. The enhanced subsidence over the central tropical Pacific suppresses the local convection activity, which in turn triggers an anomalous lowlevel anticyclone over the western North Pacific as a Gill-type Rossby-wave response (Gill 1980).

This result is consistent with previous numerical experiment result (Zuo et al. 2019), which revealed that warm SSTAs over the tropical North Atlantic favor the intensification of the WNPAC via modulating the Walker circulation over the Atlantic-Pacific Oceans in summer. Therefore, consistency between the simulations and observations confirms the impact of the North Atlantic SSTAs on the WNPAC and thus the precipitation anomalies over NEC in JA (Fig. 10c).

Previous studies have revealed that the tripole-like SSTAs in the North Atlantic can also exert an impact on the East Asian summer climate by triggering a set of wave trains propagating from the North Atlantic downward to Eurasian mid-high latitudes (Wu et al. 2009; Wu et al. 2012; Zuo et al. 2013; Li et al. 2018). 
As seen in Fig. 11a, which displays the regressed 500-hPa geopotential height anomalies in JA against the NATI, there exists a set of wave trains propagating from the North Atlantic middle latitudes downward to Northeast Asia. A similar wave-train pattern is observed in the ensemble-mean difference in $500-\mathrm{hPa}$ geopotential height between the NAT and control runs (Fig. 11b). But it should be noted that amplitude of both the observed and simulated wave-train patterns is rather weak in the Eurasian mid-high latitudes.

\section{Empirical Prediction Of Late Summer Necr}

The three predictors explored in Sect.4 include SSTAs and their trends in the tropical Pacific, TNIO and North Atlantic Ocean. The SSTAs of these oceans have a synergistic effect on the interannual NECR variability in late summer. That is, these predictors can be used to predict the latter. Thus, we developed an empirical prediction model with multiple regression using the predictors shown in Table. 1. Firstly, we established the simulation equation using 1963-2002 data, the prediction (simulation) equation is as follows:

NECRI $=0.46 \times$ WEPDTI+0.308 $\times$ TNIOI+0.111 $\times$ NATI

The meanings and definitions of the predictors are described in Table 1. The predictors are all standardized sequences. As shown in Fig. 12, the empirical prediction model can reproduce the NECRI realistically with a TCC (MSSS) skill of $0.74(0.58)$ for the period 1963-2002. The relative importance of the predictors to the overall model is ordered by WEPDTI (0.70), TNIOI (0.63), and NATI (0.53) in terms of the partial correlations in parentheses. Furthermore, we then made independent forecasts for the period 2003-2019. The TCC (MSSS) skills of independent forecast and all 59 years are $0.70(0.51)$ and $0.72(0.54)$, respectively. In addition, in order to test the predictive capability of the empirical model, the cross-validation method is performed using leaving-4-year-out and leaving-10-yearout each step (figure not shown). The TCC (MSSS) for the 59-year cross-validated reforecast skills are $0.68(0.49)$ and $0.66(0.41)$, respectively. The above TCC skills are all significant at the $99 \%$ confidence level, indicating that the empirical prediction model is skillful in predicting the interannual NECR variability in JA.

What is the current status of state-of-the-art climate models' predictions of JA NECR with a 1- or 2-month lead? Table 2 shows the JA NECR prediction performance of five current models and the MME of those five models issued in May and June. The TCC (MSSS) skills of predictions issued in May by the five models range from -0.01 to 0.26 (from -0.61 to 0.10 ) issued on May, and those of the predictions issued on June range from 0.08 to 0.38 (from -0.26 to 0.07 ). The TCC (MSSS) skills of the MME hindcast are only $0.22(0.05)$ and $0.24(0.07)$ issued on May and June, respectively, which is much lower than that of the empirical prediction model prediction. That is, compared with the precipitation directly predicted by state-of-the-art models, the predictions of the proposed empirical prediction model are obviously improved.

\section{Conclusions And Discussions}

Page $11 / 29$ 
Accurate prediction of the summer rainfall anomalies is crucial for agricultural and industrial production planning and water resource management in Northeast China (NEC). However, the skill of state-of-the-art dynamical climate models in predicting the NEC rainfall (NECR) is limited in summer. Accordingly, this paper examined the interannual variability of late summer (i.e., July-August) NECR, which accounts for approximately $80 \%$ of the NEC total summer rainfall, and then built an empirical prediction model based on oceanic drivers to predict the JA NECR with a 1-month advance lead.

SST anomalies are important basis for short-term climate prediction. Thus, we selected the key SST predictors affecting JA NECR from the global SST. And three synergistic ocean predictors in the previous winter and spring were selected. The first precursor is the spring SST anomalies in the tropical northern Indian Ocean. The warm SST anomalies in the tropical northern Indian Ocean can persist into the following summer, which help maintain and enhance the intensity of the WNPAC through the eastward propagation of Kelvin waves and/or an anomalous Hadley circulation during late summer (Yang et al. 2007; Wu and Zhou 2008; Xie et al. 2009; Li et al. 2017). The second precursor is a dipolar-like SST tendency with warming in the West Pacific and cooling in the tropical East Pacific from winter to spring, which signifies the development of an anomalous WNPAC in late summer. The third predictor is a tripolarlike SST anomaly tendency over the North Atlantic, which can persist from spring into late summer and contribute to the WNPAC and thus NECR variability in late summer. The WNPAC is the most important atmospheric circulation system that impacts the interannual variability of late summer NECR. The interannual variability of the WNPAC is mainly modulated by SST anomalies over three oceanic regions via air-sea interaction, including the western North Pacific and equatorial central-eastern Pacific Ocean, tropical northern Indian Ocean, and the North Atlantic Ocean. Numerical modeling experiments conducted with the CAM5.3 model confirm the influence of SST anomalies in these regions on the WNPAC and thus the NECR variability.

Finally, we established an empirical prediction model based on the above three physical and empirical predictors. The forecast TCC (MSSS) skill is $0.72(0.54)$ for the period of 1963-2019, and the independent forecast skill reaches 0.70 (0.51) during 2003-2019. This satisfactory forecast skill provides an estimate for the lower JA NECR prediction bound. The forecasts of five state-of-the-art climate models and their ensemble forecast show low skills; their ensemble forecast (for the period of 1979-2019) TCC (MSSS) skills are $0.22(0.05)$ and $0.24(0.07)$ at 1- month and 2- month lead time, respectively. These results suggest that there is considerable room for improvement of NECR dynamical prediction, whereas the proposed empirical prediction model is a meaningful approach for the NECR prediction.

Generally, the EASM arrives in NEC in mid-July, resulting in the onset of monsoon rains therein (Lian et al. 2003). Thus, one could define late summer as July 15 th-August. However, the difference is expected to be small when compared to JA, and the use of JA is more convenient for issuing climate forecasts to the public. In addition to monsoon rainfall, the summer precipitation in NEC also includes cold vortex rainfall and typhoon rainfall (Chen et al. 2020). Hence, the prediction skill may be further improved if different properties of rainfall are distinguished and predicted by separate predictors. Moreover, as Zhao et al. (2018) reported, JA NECR has significant interannual and interdecadal variability, and variations on 
different time scales are associated with different circulation patterns. Thus, it is appropriate to predict the variability of individual components by different approaches. Furthermore, the preponderance of the time-scale decomposition approach in the statistical forecast of summer rainfall over North China has been proven by Guo et al. (2012). Opposite phases between observations and predictions is only observed in 2007 and 2016 during the independent forecast periods in our current oceanic drivers and empirical prediction model. The NECR anomaly in these two years may be related to other forcing, such as the Tibetan Plateau snow cover, which is also an important factor affecting East China climate variability (Wu et al. 2012; Jin et al. 2018). Therefore, in the future, we will establish more advantageous empirical prediction models to improve the forecast skills of summer NECR on the basis of the above two approaches and more predictors.

\section{Declarations}

Acknowledgements The authors are grateful to the anonymous reviewers and editor for their insightful comments to improve the quality of the paper. This work is supported by the National Key Research and Development Program on Monitoring, Early Warning and Prevention of Major Natural Disaster (2018YFC1506005) and the National Natural Science Foundations of China (Grant No. 41875093, 41975102, 42075017, 41975098 and 41705074).

\section{Reference}

1. Blockeel H, Struyf J (2003) Efficient algorithms for decision tree crossvalidation. J Mach Learn Res 3: 621-650.

2. Chen MY, Xie PP, Janowiak JE et al (2002) Global land precipitation: A 50-yr monthly analysis based on gauge observations. J Hydrometeorol 3: 249-266.

3. Chen Z, Zhang J (2020) The characteristics of late summer extreme precipitation in northern China and associated large-scale circulations. Int J Climatol 1-18. https://doi:10.1002/joc.6512

4. Du Y, Xie SP, Huang G, et al. (2009) Role of air-sea interaction in the long persistence of El Niñoinduced North Indian Ocean warming. J Climate, 22: 2023-2038. doi:10.1175/2008JCLI2590.1

5. Fang YH, Chen KQ, Chen HS, et al. 2018. The remote responses of early summer cold vortex precipitation in northeastern China compared with the previous sea surface temperatures. Atmos Res 214: 399-409.

6. Forbes AMG (1988) Fourier transform filtering: A cautionary note. J Geophys Res 6958-6962.

7. Gao ZT, Hu ZZ, Jha B, Yang S, Zhu JS, Shen BZ, Zhang RJ (2014a) Variability and predictability of Northeast China climate during 1948-2012. Clim Dyn 43: 787-804. https:// doi:10.1007/s00382013-1944-0

8. Gao ZT, Hu ZZ, Zhu JS, Yang S, Zhang RJ, Xiao ZN, Jha B (2014b) Variability of summer rainfall in Northeast China and its connection with spring rainfall variability in the Huang-Huai region and Indian Ocean SST. J Clim 27: 7086-7101. https://doi:10.1175/JCLI-D-14-00217.1 
9. Gill AE (1980) Some simple solutions for the heat induced tropical circulation. Q J Meterol Soc 106: 447-462. https ://doi.org/10.1002/qj.49710 644905

10. Guo Y, Li JP, Li Y (2012) A time-scale decomposition approach to statistically downscale summer rainfall over North China. J Clim 25: 572-591. https://doi:10.1175/JCLI-D-11-00014.1

11. Ham YG, Kug JS, Park JY, et al (2013) Sea surface temperature in the north tropical Atlantic as a trigger for El Nino/Southern Oscillation events. Nat Geosci 6: 112-116.

12. Han TT, Chen HP, Wang HJ (2015) Recent changes in summer precipitation in Northeast China and the background circulation. Int J Climatol 35: 4210-4219. https://doi:10.1002/joc.4280

13. He JH, Wu ZW, Jiang Z, Han G (2007) "Climate effect" of the northeast cold vortex and its influences on Meiyu. Chin Sci Bull 51: 671-679. https://doi:10.1007/s11434-007-0053-Z.

14. Hong CC, Chang TC, Hsu HH (2014) Enhanced relationship between the tropical Atlantic SST and the summertime western North Pacific subtropical high after the early 1980s. J Geophys Res 119: 37153722.

15. Hong C-C, Lee M-Y, Hsu H-H, Lin N-H, Tsuang B-J (2015) Tropical SST forcing on the anomalous WNP subtropical high during July-August 2010 and the record-high SST in the tropical Atlantic. Clim Dyn 45: 633-650. https ://doi.org/10.1007/s00382-014-2275-5

16. Hu KX, Lu RY, Wang DH (2010) Seasonal climatology of cut-off lows and associated precipitation patterns over Northeast China. Meteorol Atmos Phys 106: 37-48. https://doi:10.1007/s00703-0090049-0

17. Huang BH, Kinter III JL (2002) Interannual variability in the tropical Indian Ocean. J Gerophys Res 107: 20-1-20-26. doi:10.1029/2001JC001278

18. Huang JP, Yi YH, Wang SW, Chou JF (1993) An analogue-dynamical long-range numerical weather prediction system incorporating historical evolution. Q J R Meteorol Soc 119: 547-565. https://doi:10.1002/qj.49711951111

19. Hurrell JW, Holland MM, Gent PR, et al (2013) The community earth system model: a framework for collaborative research. Bull Amer Meteor Soc 94: 1339-1360. https://doi.org/10.1175/BAMS-D-1200121.1

20. Jin R, Wu ZW, Zhang P (2018) Tibetan Plateau capacitor effect during the summer preceding ENSO: from the Yellow River climate perspective. Clim Dyn 51: 57-71. https://doi:10.1007/s00382-0173906-4

21. Kalnay E, Kanamitsu M, Kistler R, et al (1996) The NCEP/NCAR 40-year reanalysis project. Bull Amer Meteor Soc 77: 437-472. https://doi:10.1175/1520-0477(1996)077<0437:TNYRP>2.0.C0;2

22. Kim Hye-Mi, Webster Peter J, and Curry Judith A (2012) Seasonal prediction skill of ECMWF System 4 and NCEP CFSv2 retrospective forecast for the Northern Hemisphere Winter. Clim Dyn 39: 29572973. https://doi:10.1007/s00382-012-1364-6

23. Li J, Wang B (2015) How predictable is the anomaly pattern of the Indian summer rainfall? Clim Dyn 46: $2847-2861$ 
24. Li J, Wang B (2018) Predictability of summer extreme precipitation days over eastern China. Clim Dyn 51: 4543-4554. https://doi:10.1007/s00382-017-3848-x

25. Li JP, Wu ZW, Jiang Z, He JH (2010) Can global warming strengthen the East Asian summer monsoon? J Clim 23: 6696-6705. https://doi:10.1175/2010JCLI3434.1.

26. Li JP, Zeng QC (2002) A unified monsoon index. Geophys Res Lett 29: 1274. https://doi:10.1029/2001GL013874

27. Li T, Wang B, Wu B, Zhou TJ, Chang Chih-Pei, Zhang RH (2017) Theories on formation of an anomalous anticyclone in western North Pacific during El Niño: a Review. J Meteor Res 31: 9871006. doi: 10.1007/s13351-017-7147-6

28. Li WJ, Ren HC, Zuo JQ, Ren HL (2018) Early summer southern China rainfall variability and its oceanic drivers. Clim Dyn 50: 4691-4705. https ://doi.org/10.1007/s0038 2-017-3898-0

29. Lian Y, Shen BZ, Gao ZT, An G, Tang XL (2003) The study of the on-set criterion and the date of East Asian summer monsoon in Northeast China and its main characteristic analysis. Acta Meteorol Sin (in Chinese) 61: 548-558.

30. MacLachlan C, Arribas A, Peterson KA, et al (2015) Global Seasonal forecast system version 5 (GloSea5): a high-resolution seasonal forecast system. Q J R Meteorol Soc 141: 1072-1084. https://doi:10.1002/qj.2396

31. Michaelsen J (1987) Cross-validation in statistical climate forecast models. J Climate Appl Meteorol 26: $1589-1600$.

32. Reynolds R W, Rayner N A, Smith T M, et al (2002) An improved in situ and satellite SST analysis for climate. J Clim 15: 1609-1625. https://doi:10.1175/1520-0442(2002)015<1609:AllSAS>2.0.C0;2

33. Saha S, Moorthi S, Wu XR, et al (2014) The NCEP climate forecast system version 2. J Clim 27: 2185-2208. https://doi:10.1175/JCLI-D-12-00823.1

34. Shen BZ, Lin ZD, Lu RY, Lian Y (2011) Circulation anomalies associated with interannual variation of early- and late-summer precipitation in Northeast China Sci Earth Sci 54: 10951104. https://doi:10.1007/s11430-011-4173-6

35. Sui C-H, Chung P-H, Li T (2007) Interannual and interdecadal variability of the summertime western North Pacific subtropical high. Geophys Res Lett 34: L11701. https://doi:10.1029/2006GL029204

36. Sun $L$, An G, Ding L, et al (2000) A climatic analysis of summer precipitation features and anomaly in northeast China. Acta Meteorol Sin (in Chinese) 58: 70-82.

37. Sun L, An G, Tang XL (2003) Relationship between the northeast Asian summer south wind anomaly and the precipitation in northeast China. Chin Atmos Sci (in Chinese) 27: 425-434.

38. Sun L, Shen BZ, Sui Bo, Huang BH (2017) The influences of East Asian Monsoon on summer precipitation in Northeast China. Clim Dyn 48: 1647-1659. https://doi:10.1007/s00382-016-3165-9

39. Takaya Y, Hirahara S, Yasuda T, et al (2018) Japan Meteorological Agency/Meteorological Research Institute-Coupled Prediction System version 2 (JMA/MRI-CPS2): atmosphere-land-ocean-sea ice 
coupled prediction system for operational seasonal forecasting. Clim Dyn 50: 751765. https://doi: 10.1007/s00382 -017-3638-5

40. Wang B, Lee JY et al (2009) Advance and prospect of seasonal prediction: Assessment of APCC/CliPAS 14-model ensemble retrospective seasonal prediction (1980-2004). Clim Dyn 33: 93117. https://doi: 10.1007/S00382-008-0460-0

41. Wang B, Xiang BQ, Lee JY (2013) Subtropical high predictability establishes a promising way for monsoon and tropical storm predictions. Proc Natl Acad Sci USA, 110: 2718-2722.

42. Wen X, Wang B, Yim S-Y, Ha K-J (2017) Predictable patterns of the May-June rainfall anomaly over East Asia, J. Geophys Res Atmos 122: 2203-2217. https://doi:10.1002/2016JD025856

43. WMO (2002) Standardised verification system for longrange forecasts (LRF): new attachment II-9 to the manual on the GDPS, WMO No. 485. WMO, Geneva.

44. Wu B, Li TM, Zhou T (2010) Relative contributions of the Indian Ocean and local SST anomalies to the maintenance of the western North Pacific anomalous anticyclone during the El Niño decaying summer. J Clim 23: 2974-2986

45. Wu B, Zhou T (2008) Oceanic origin of the interannual and interdecadal variability of the summertime western Pacific subtropical high. Geophys Res Lett 35: L13701.

46. Wu TW, Li WP, Li JJ et al (2013) Global carbon budgets simulated by the Beijing climate center climate system model for the last century. J Geophys Res: Atmos 118: 1-22.

47. Wu ZW, Li JP (2008) Prediction of the Asian-Australian monsoon interannual variations with the gridpoint atmospheric model of IAP LASG (GAMIL). Adv Atmos Sci 25: 387-

394. https://doi:10.1007/s00376-008-0387-8

48. Wu ZW, Li JP, Jiang ZH, Ma TT (2012) Modulation of the Tibetan Plateau snow cover on the ENSO teleconnections: From the East Asian summer monsoon perspective. J Clim 25: 24812489. https://doi:10.1175/JCLI-D-11-00135.1.

49. Wu ZW, Wang B, Li JP, Jin F-F (2009) An empirical seasonal prediction model of the East Asian summer monsoon using ENSO and NAO. J Geophys Res 114:

D18120.https://doi:10.1029/2009JD011733

50. Wu ZW, Yu LL (2016) Seasonal prediction of the East Asian summer monsoon with a partial-least square model. Clim Dyn 46: 3067-3078. https://doi:10.1007/s00382-015-2753-4.

51. Xiang B, Wang B, Yu W, Xu S (2013) How can anomalous western North Pacific Subtropical High intensify in late summer? Geophys Res Lett 40: 2349-2354. https://doi:10.1002/grl.50431

52. Xie SP, Hu KM, Hafner J, et al (2009) Indian Ocean capacitor effect on Indo-Western Pacific climate during the summer following El Niño. J Clim 22: 730-747. https://doi:10.1175/2008JCLI2544.1

53. Yang JL, Liu QY, Xie SP, et al (2007) Impact of the Indian Ocean SST basin mode on the Asian summer monsoon. Geophys Res Lett 34: L02708

54. Yim S-Y, Wang B, Xing W (2014) Prediction of early summer rainfall over South China by a physicalempirical model. Clim Dyn 43: 1883-1891. https://doi:10.1007/s00382-013-2014-3 
55. Yim S-Y, Wang B, Xing W, Lu M-M (2015) Prediction of Meiyu rainfall in Taiwan by multi-lead physical-empirical models. Clim Dyn 44: 3033-3042. https://doi:10.1007/s00382-014-2340-0

56. Zhao JH, Xiong KG, Chen LJ (2020) The reason of low predictive skills of precipitation in flood season in Northeast China. Chin Atmos Sci (in Chinese) 44: 913-

934. https://doi:10.3878/j.issn.1006-9895.1911.19132

57. Zhao JH, Zhou J, Xiong KG, Hou W, Feng GL (2019) Relationship between tropical Indian ocean SSTA in spring and precipitation of Northeast China in late summer. J Meteor Res 33: 1060-1074. https://doi: 10.1007/s13351-019-9026-9

58. Zhao JH, Zhou J, Yang L, Hou W, Feng GL (2018) Interannual and interdecadal variability of earlyand late-summer precipitation over Northeast China and their background circulation. Int $\mathrm{J}$ Climatol 38: 2880-2888. https://doi: 10.1002/joc.5470

59. Zuo JQ, Li WJ, Sun CH, Xu L, Ren HL (2013) Impact of the North Atlantic sea surface temperature tripole on the East Asian summer monsoon. Adv Atmos Sci 30: 1173-1186. https://doi:

10.1007/s00376-012-2125-5

60. Zuo JQ, Li WJ, Sun CH, Ren HC (2019) Remote forcing of the northern tropical Atlantic SST anomalies on the western North Pacific anomalous anticyclone. Clim Dyn 52: 2837-2853. https://doi.org/10.1007/s00382 -018-4298-9

\section{Tables}

\section{Table 1 Definitions of the 1-month lead predictors selected for the prediction of JA NECR variability}

\begin{tabular}{|c|c|c|c|}
\hline Name & Meaning & Definition & Corr \\
\hline TNIOI & MAM TNIO SST index & $\operatorname{DSST}\left(0-15^{\circ} \mathrm{N}, 50^{\circ}-120^{\circ} \mathrm{E}\right)$ & $0.63^{*}$ \\
\hline \multirow[t]{2}{*}{ WEPDTI } & \multirow{2}{*}{$\begin{array}{l}\text { MAM-minus-DJF tropical } \\
\text { West-East Pacific dipole SST } \\
\text { tendency index }\end{array}$} & DSST $\left(0-20^{\circ} \mathrm{N}, 130^{\circ}-150^{\circ} \mathrm{E}\right)-\mathrm{DSST}$ & \multirow[t]{2}{*}{$0.70 *$} \\
\hline & & $\left(5^{\circ} \mathrm{S}-10^{\circ} \mathrm{N}, 170^{\circ} \mathrm{E}-120^{\circ} \mathrm{W}\right)$ & \\
\hline NATI & $\begin{array}{l}\text { MAM-minus-DJF North } \\
\text { Atlantic tripolar SST index }\end{array}$ & $\begin{array}{l}\text { DSST }\left(0-20^{\circ} \mathrm{N}, 50^{\circ} \mathrm{W}-20^{\circ} \mathrm{W}\right)+\mathrm{DSST}\left(46^{\circ}-\right. \\
\left.60^{\circ} \mathrm{N}, 60^{\circ} \mathrm{W}-20^{\circ} \mathrm{W}\right)-2^{\star} \mathrm{DSST}\left(26^{\circ}-34^{\circ} \mathrm{N},\right. \\
\left.50^{\circ} \mathrm{W}-30^{\circ} \mathrm{W}\right)\end{array}$ & $0.53 *$ \\
\hline
\end{tabular}

Annotation: the "Corr" indicates the correlation coefficients between the JA NECRI and SST predictors during 1963-2002; * denotes significance at the 95\% confidence levels.

\section{Table 2 TCC and MSSS skills for JA NECR based on observations and seasonal prediction by various models}




\begin{tabular}{|llllll|}
\hline Models & Time range & \multicolumn{2}{l|}{ Issued in May } & \multicolumn{2}{l|}{ Issued in June } \\
\hline & & TCC & MSSS & TCC & MSSS \\
\hline Empirical prediction model & $1963-2019$ & -- & -- & $\mathbf{0 . 7 2}$ & $\mathbf{0 . 5 4}$ \\
\hline BCC-CSM1.1 & $1991-2019$ & 0.07 & -0.61 & 0.38 & -0.21 \\
\hline NCEP-CFSv2 & $1982-2019$ & 0.24 & 0.05 & 0.08 & -0.24 \\
\hline ECMWF4 & $1981-2019$ & 0.26 & -0.01 & 0.28 & -0.08 \\
\hline GloSea5 & $1993-2019$ & 0.25 & 0.10 & 0.26 & 0.07 \\
\hline JMA-CPSv2 & $1979-2019$ & -0.01 & -0.26 & 0.15 & -0.26 \\
\hline MME & $1979-2019$ & 0.22 & 0.05 & 0.24 & 0.07 \\
\hline
\end{tabular}

Figures 
(a) Cli JA precipitation, H500, UV850

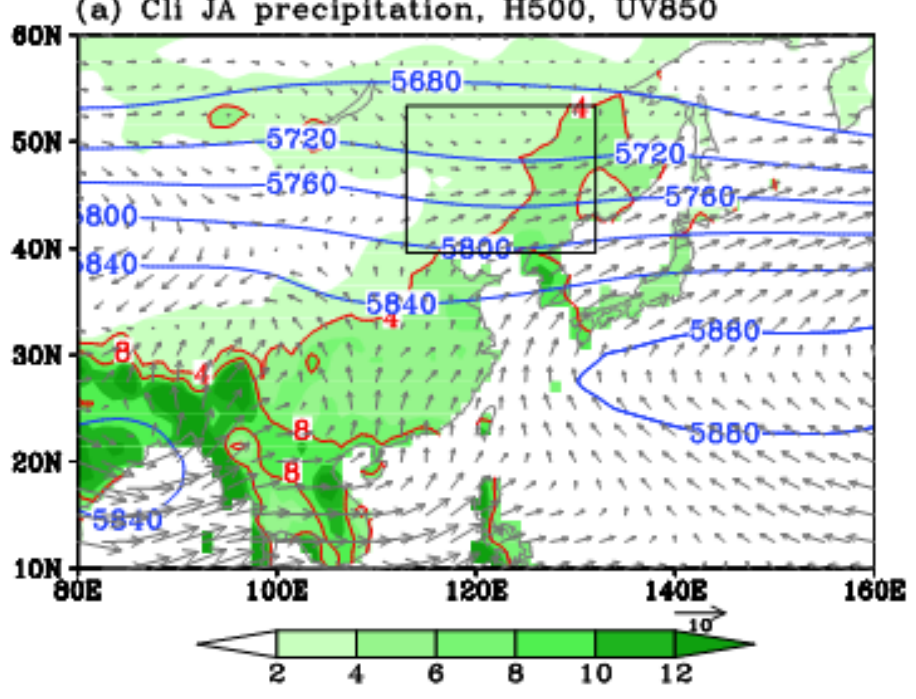

(b) IAV SD of JA Precip.

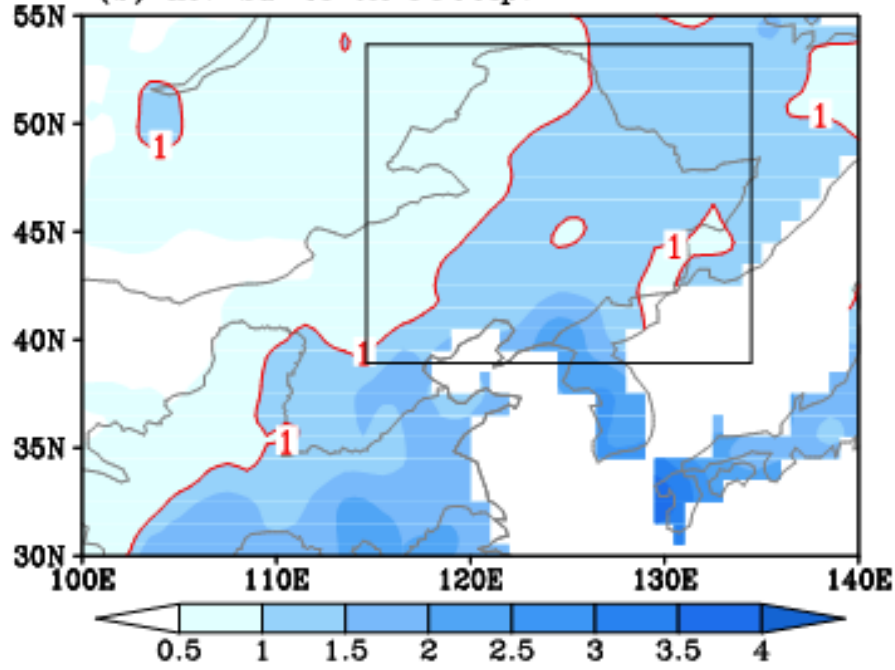

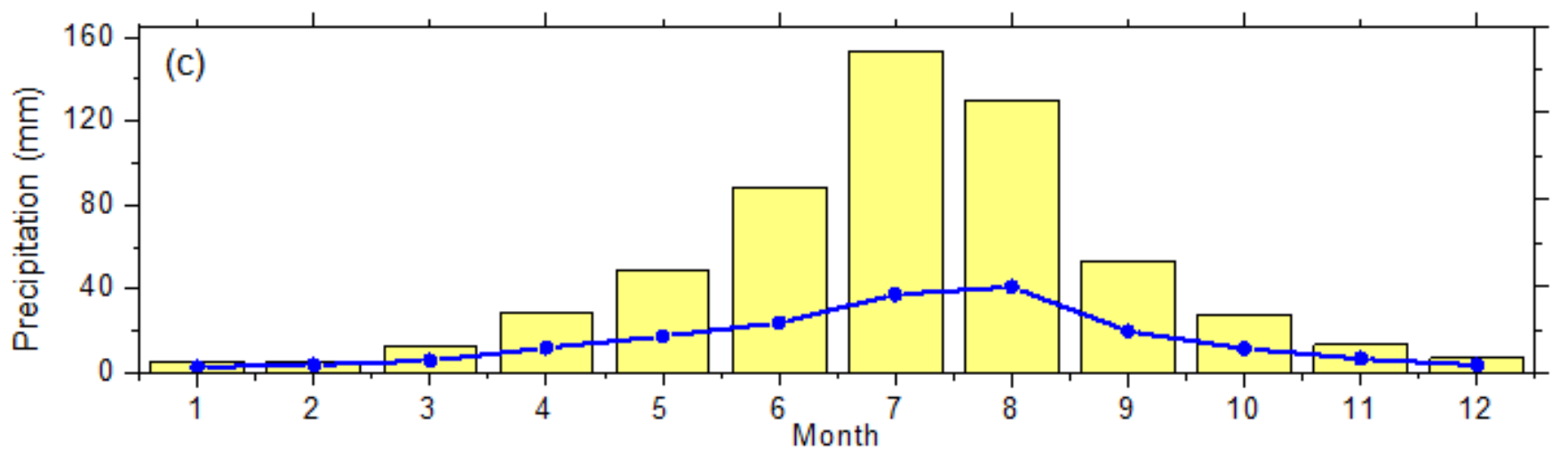

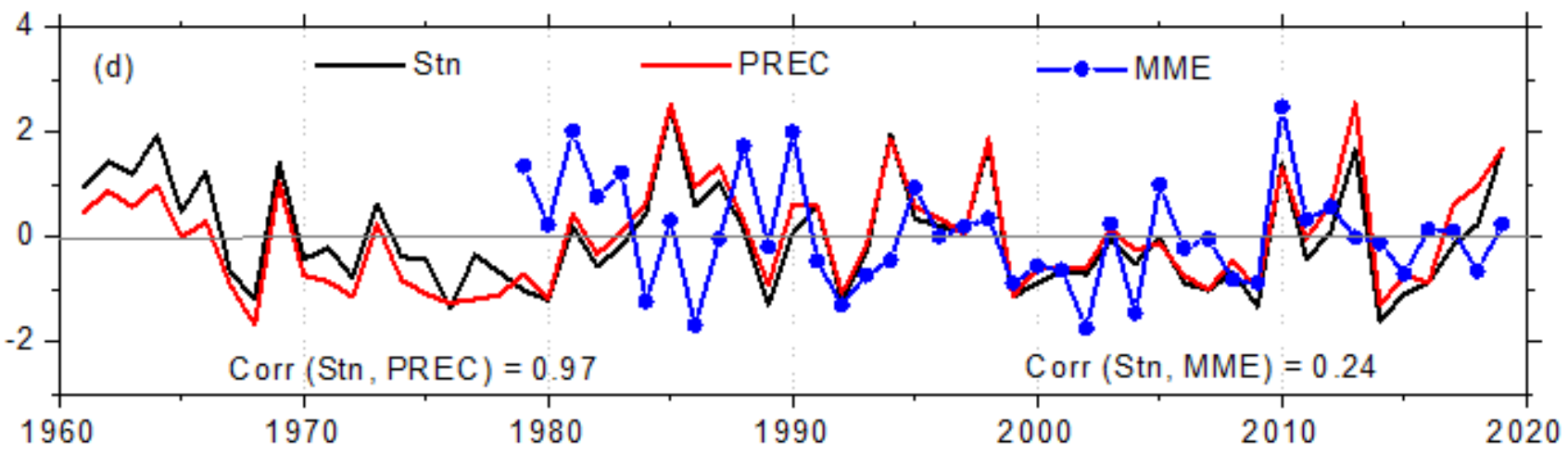

Figure 1

a Climatological mean precipitation (unit: $\mathrm{mm}$ day -1$), 500-\mathrm{hPa}$ geopotential height ( $\mathrm{H} 500$, contours; unit: gpm) and 850-hPa winds (UV850; vectors; unit: $\mathrm{m} \mathrm{s} \mathrm{-1)} \mathrm{in} \mathrm{JA.} \mathrm{b} \mathrm{Standard} \mathrm{deviation} \mathrm{of} \mathrm{the}$ interannual variability of JA precipitation (unit: $\mathrm{mm}$ day -1 ). c Monthly distribution of NEC rainfall (bar; unit: $\mathrm{mm}$ ) and its standard deviation (blue dotted line; unit: $\mathrm{mm}$ ) from January to December. $\mathrm{d}$ Time series of the NEC rainfall index (NECRI) derived from data recorded at 247 stations (black) and the multimodel retrospective prediction of the NECRI (blue). The black box in b indicates the NEC region (38- 
$53^{\circ} \mathrm{N}, 115-132.5^{\circ} \mathrm{E}$ ) where NOAA Precipitation Reconstruction (PREC) data (red) are used to compute the area-averaged NECRI. The ensemble means of five coupled models initiated from the first day of June for the 39 years spanning 1981-2019 are used. The PREC data used in a and b were from the period of 1981-2010.

(a) Regressed SST in JA
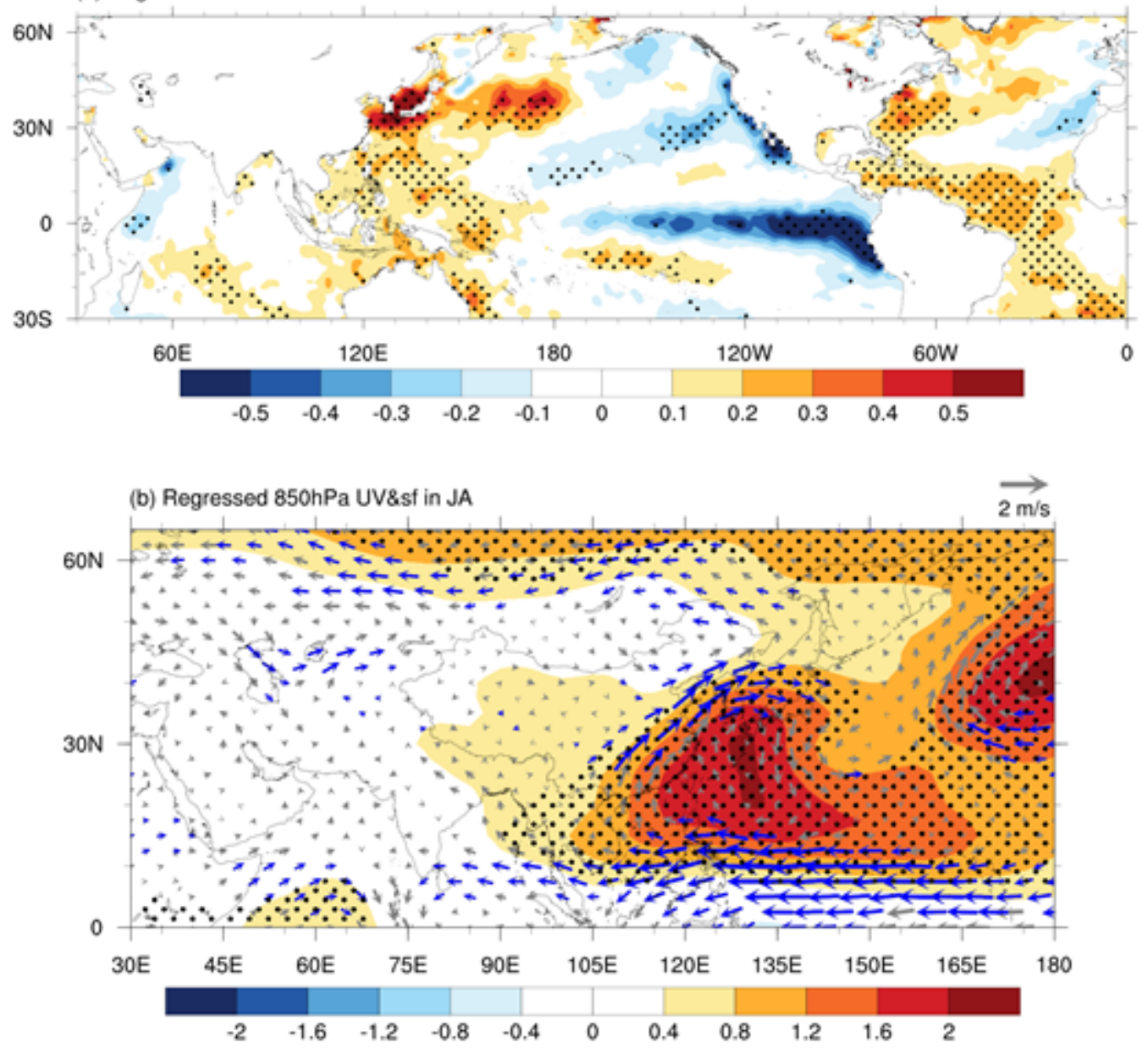

(c) Regressed PREC in JA

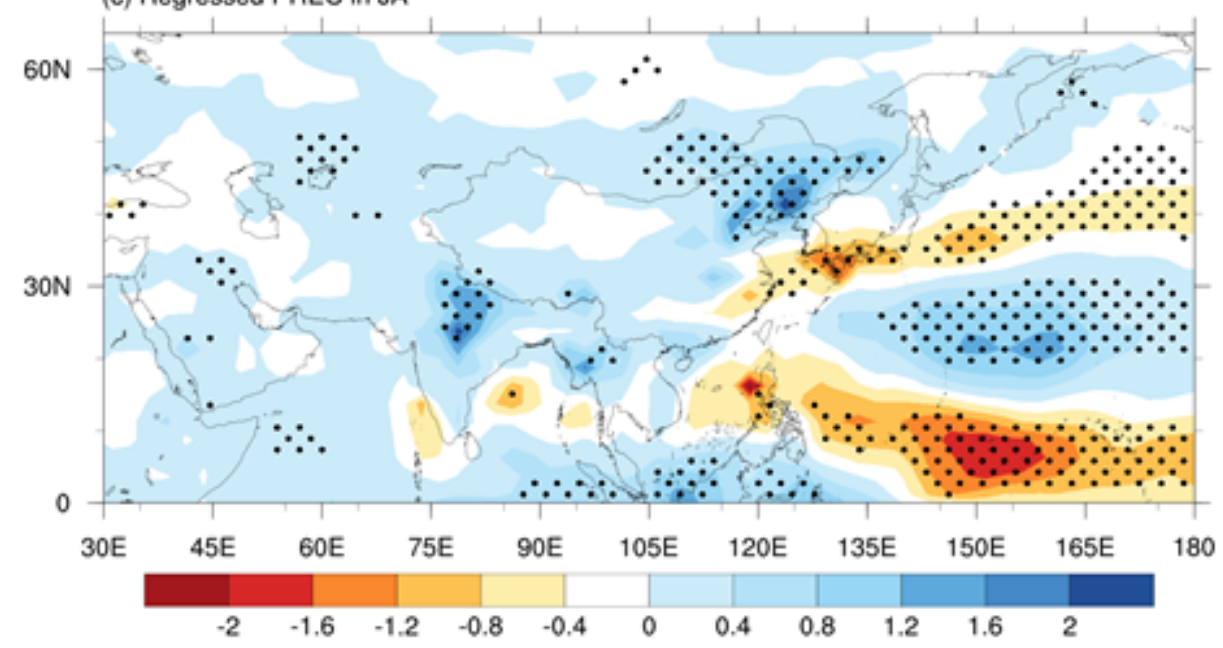

Figure 2 
Simultaneous regressions of a SST (unit: ${ }^{\circ} \mathrm{C}$ ), b stream function (shaded; unit: $105 \mathrm{~m} 2 \mathrm{~s}-1$ ) and horizontal wind (vectored; unit: $\mathrm{m} \mathrm{s}-1$ ) at $850 \mathrm{hPa}$, and c precipitation (unit: $\mathrm{mm}$ day -1 ) anomalies against the JA NECR index during the period of 1961-2019. The dots and blue vectors indicate significance at the $95 \%$ confidence level.

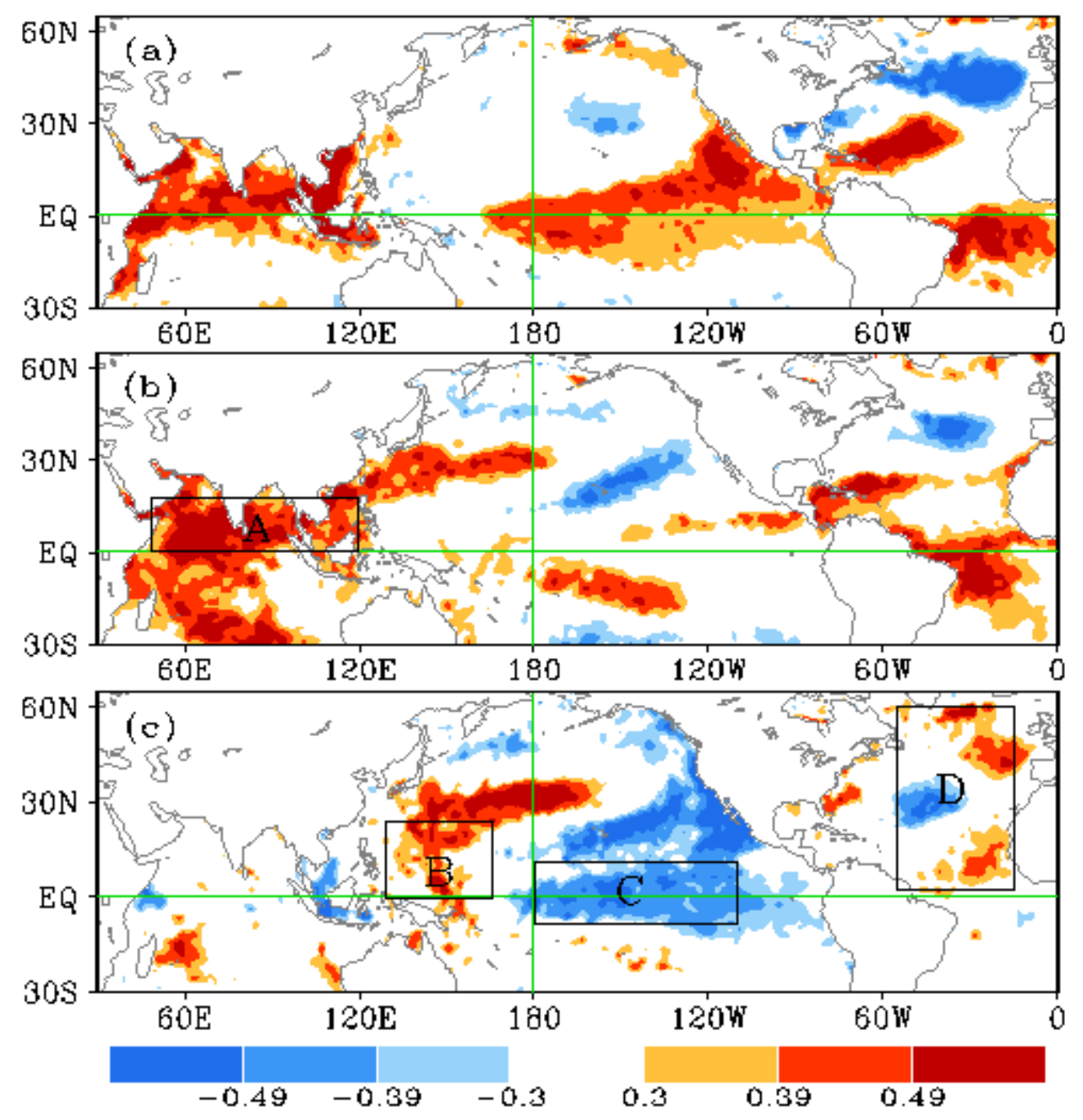

Figure 3

Correlation between the JA NECRI and SST in a DJF, b MAM, and $c$ tendency (MAM minus DJF) SST during 1963-2002. The shaded areas indicate confidence levels of $95 \%, 99 \%$ and $99.9 \%$. The boxes indicate the areas where the area-averaged SSTs are selected for the predictors. A, B, C and D indicate the tropical and northern Indian Ocean, West Pacific, tropical central-East Pacific Ocean and North Atlantic, respectively. 

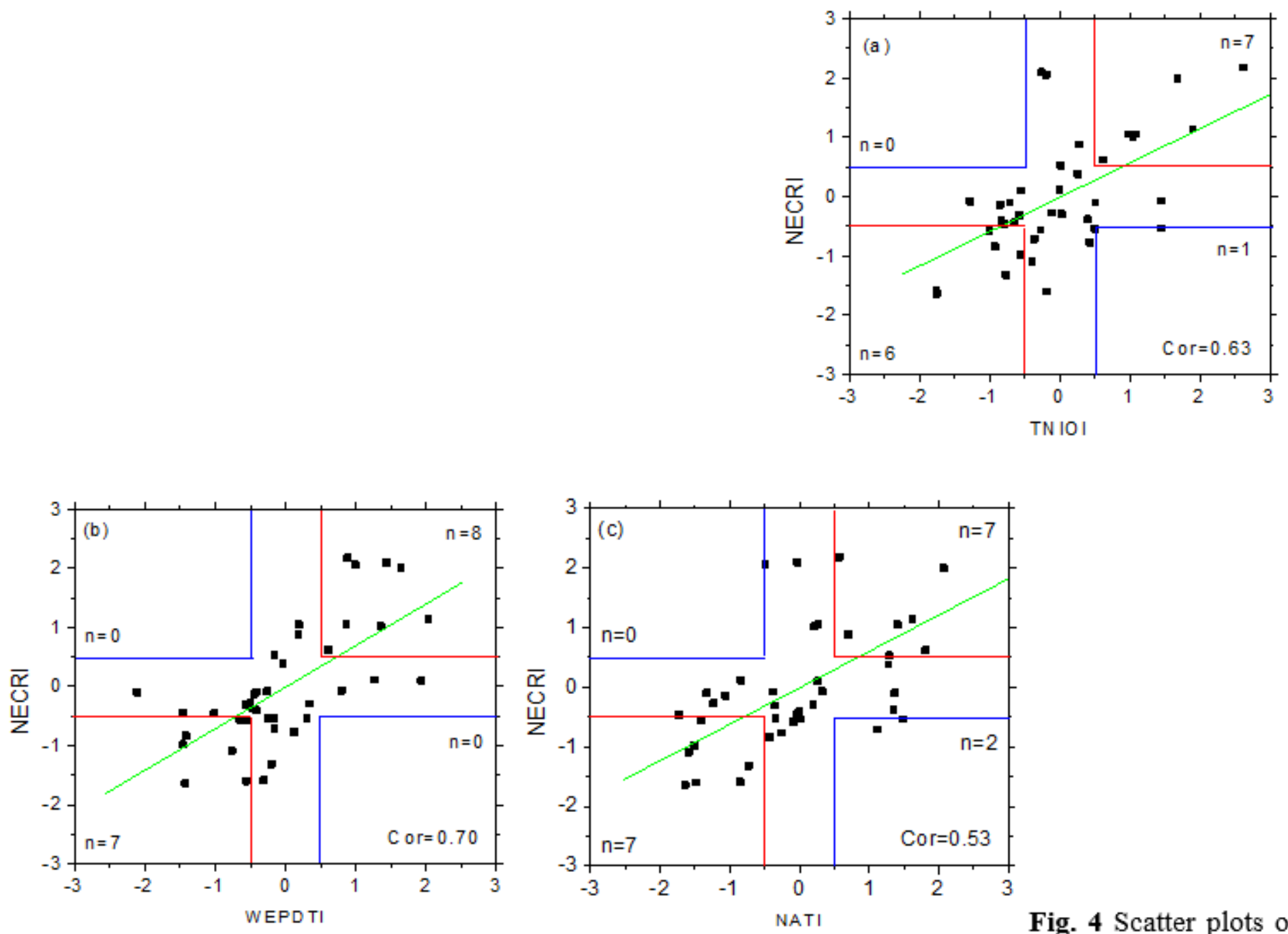

Fig. 4 Scatter plots of

\section{Figure 4}

Scatter plots of the normalized JA NECRI versus the normalized a TNIOI, b WEPDTI, and c NATI for the period of 1963-2002. The abscissa (ordinate) of each diagram represents the amplitude and sign of the SST index (JA NECRI). The number of positive (negative) SST indices with above-normal (below-normal) JA NECRI values is shown in the upper right (lower left) corner of each diagram. The number of positive (negative) SST indices with below-normal (above-normal) JA NECRI values is shown in the lower right (upper left) corner of each diagram. The correlation coefficient between the SST index and JA NECRI is shown in the lower right corner of each diagram. The green line represents linear fitting. 
(a) Regressed SST in JA
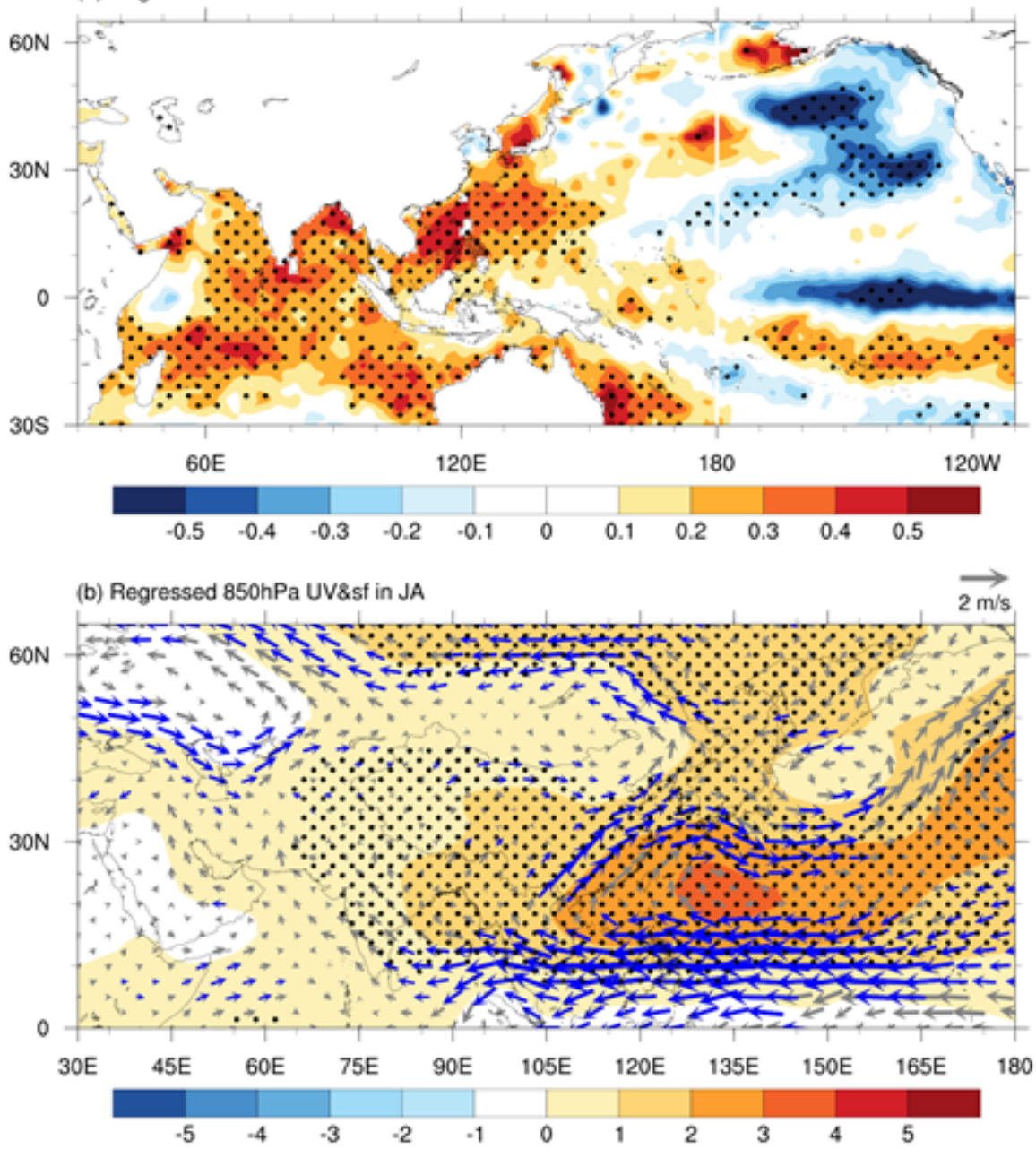

(c) Regressed PREC in JA

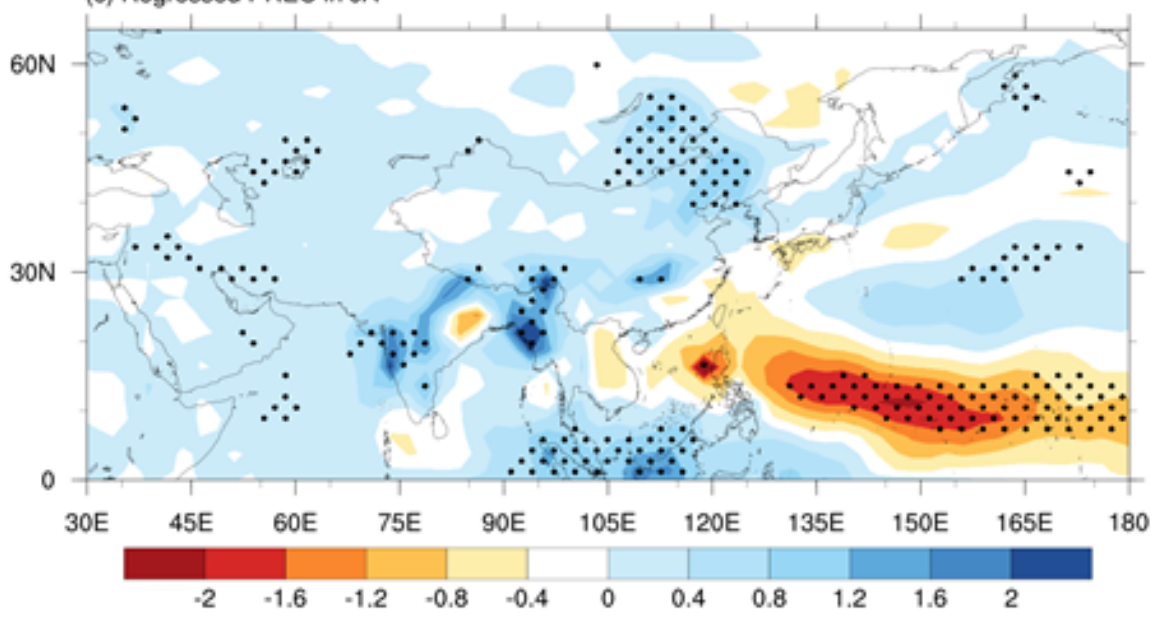

Figure 5

Same as Fig. 2 but for the MAM TNIOI during the period of 1963-2002. 
(a) SF850 \& UV850 in JA

TNIO Run

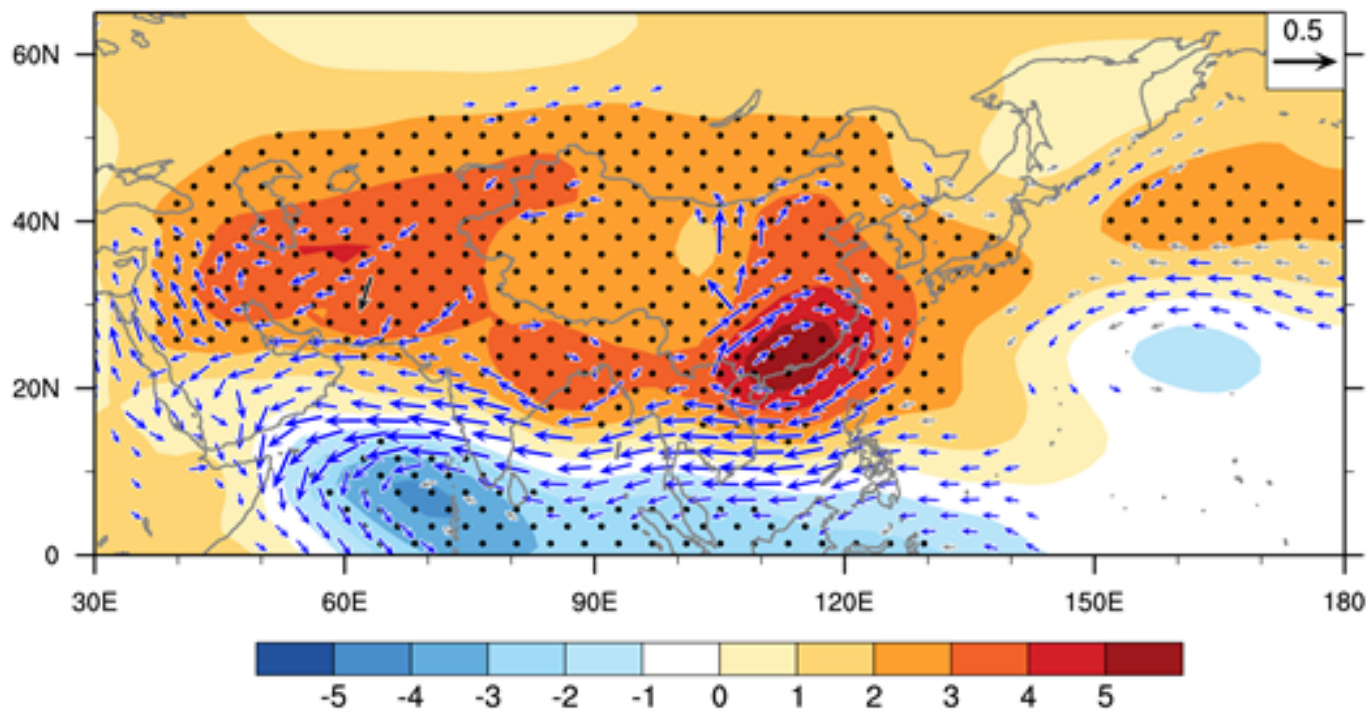

(b) PREC in JA

TNIO Run

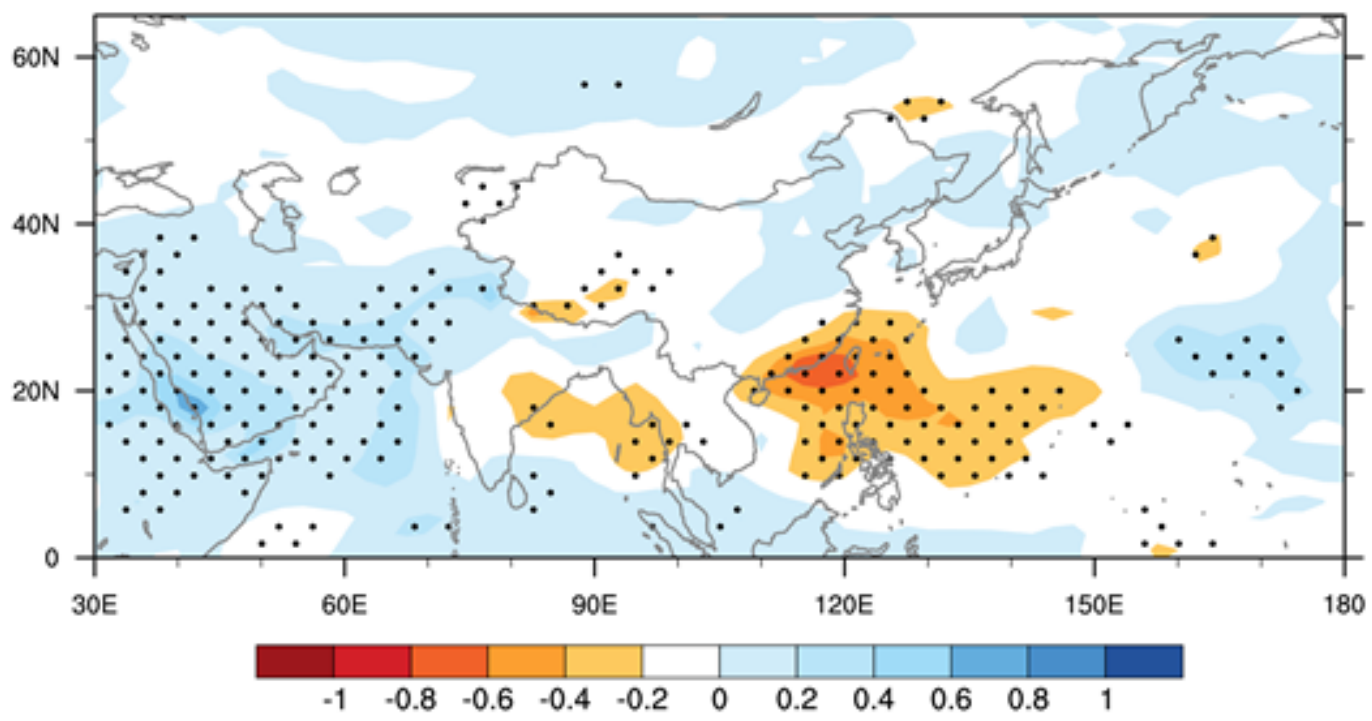

Figure 6

Same as Figs. 5b-c, but for the ensemble-mean difference between the TNIO and control runs (former minus latter). 
(a) Regressed SST in JA
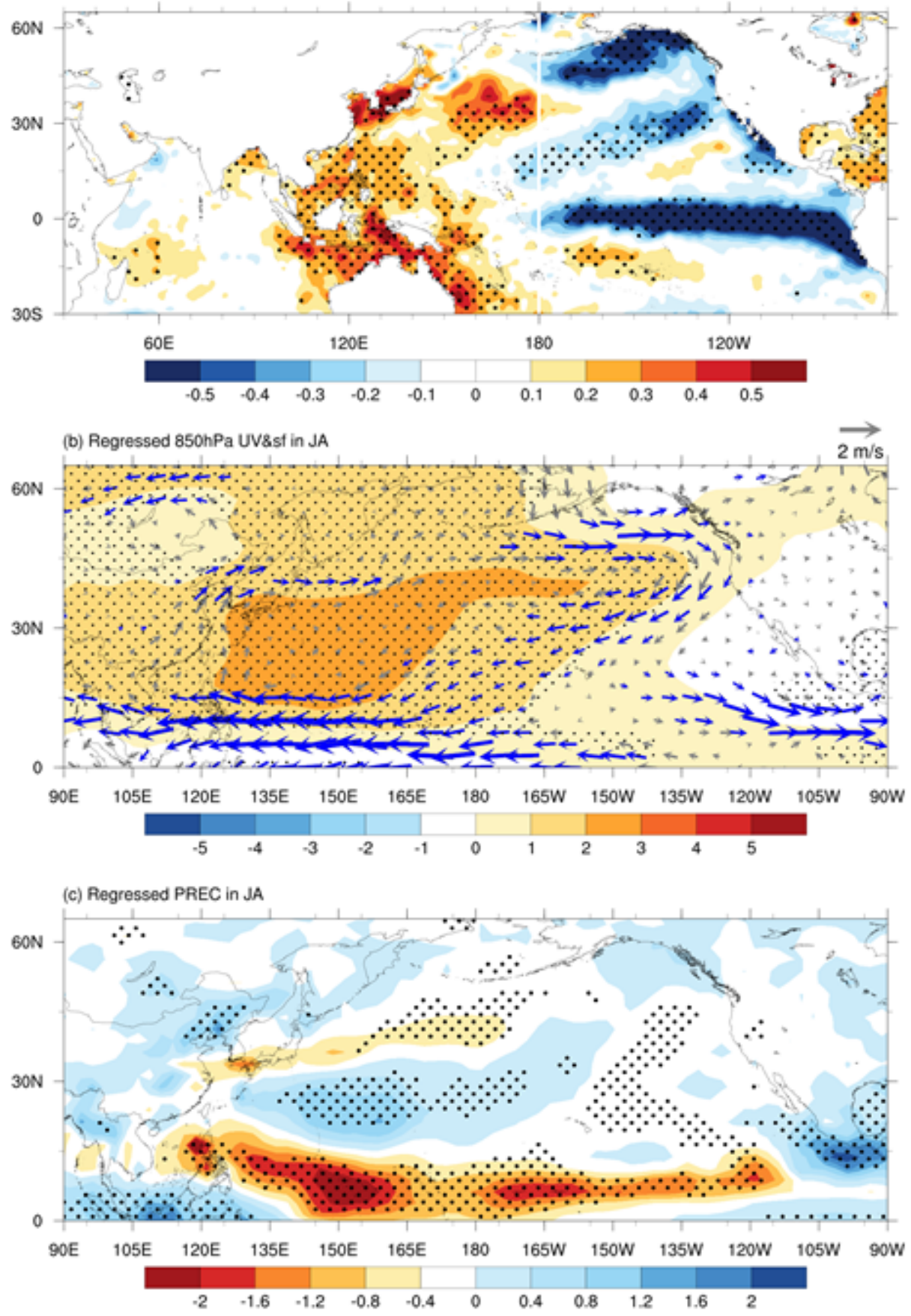

\section{Figure 7}

Same as Fig. 2 but for the WEPDTI during the period of 1963-2002. 


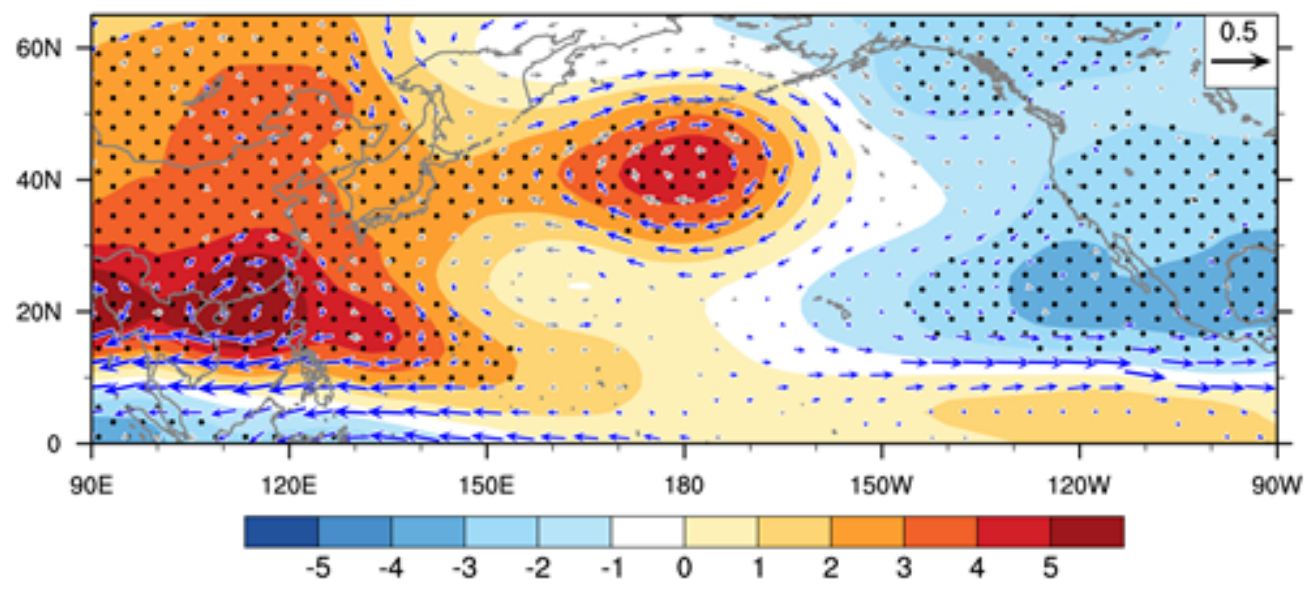

(b) PREC in JA

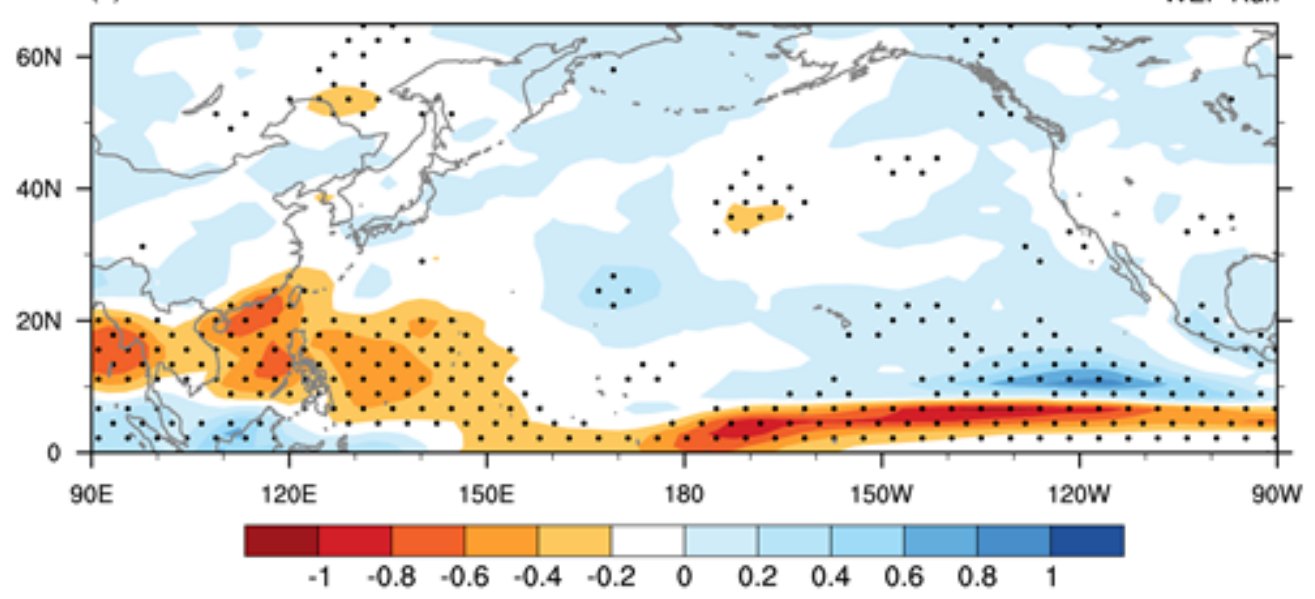

Figure 8

Same as Figs. 7b-c, but for the ensemble-mean difference between the WEP and control runs (former minus latter). 

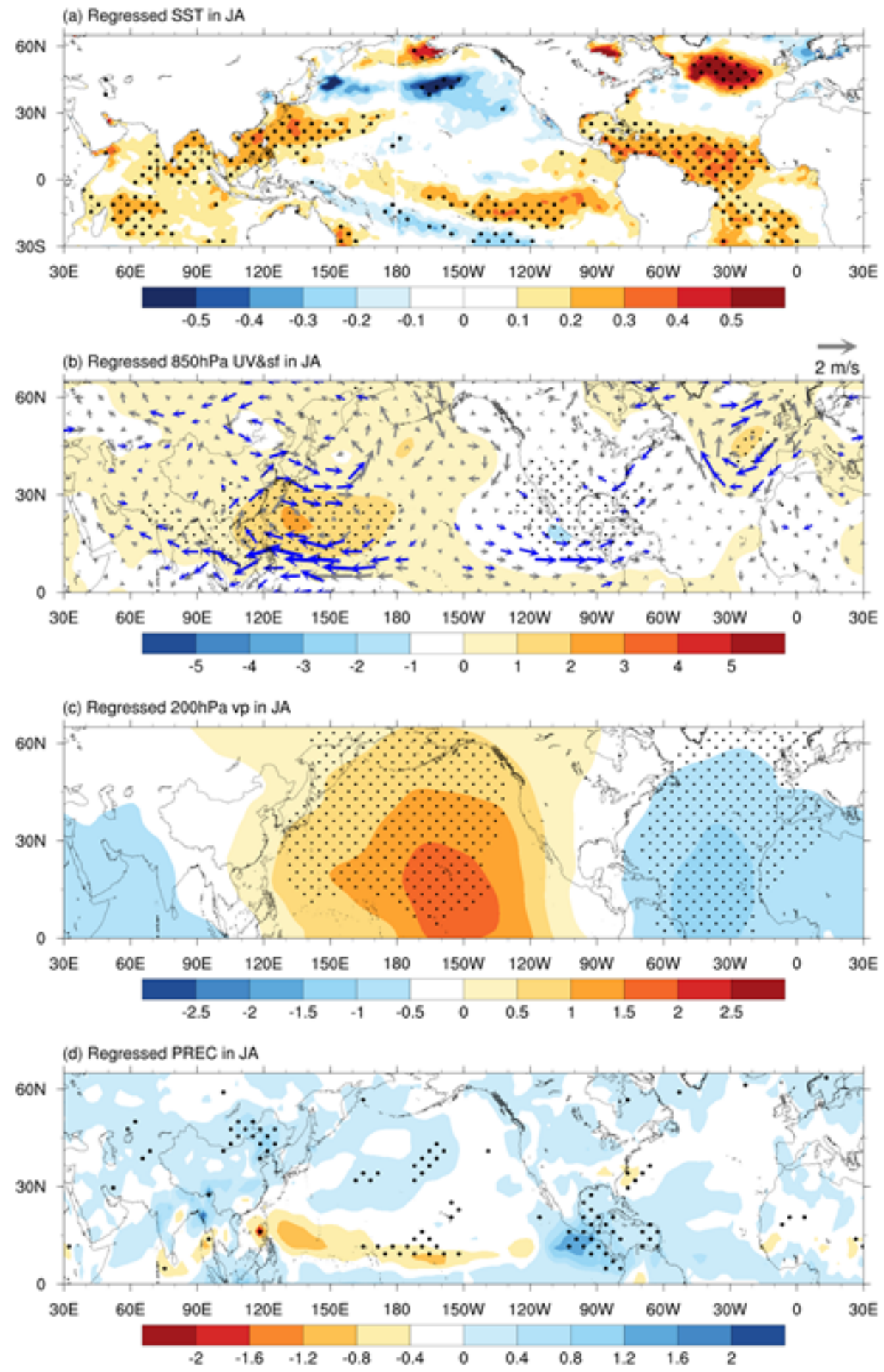

\section{Figure 9}

Regressions of a SST (unit: ${ }^{\circ} \mathrm{C}$ ), b 850-hPa stream function (shaded; unit: $105 \mathrm{~m} 2 \mathrm{~s}-1$ ) and horizontal wind (vectored; m s -1), c 200-hPa velocity potential (unit: $105 \mathrm{~m} 2 \mathrm{~s}-1$ ) and d precipitation (unit: mm day -1) anomalies in JA against the NATI during the period of 1963-2002. The dots and blue vectors indicate significance at the $95 \%$ confidence level. 


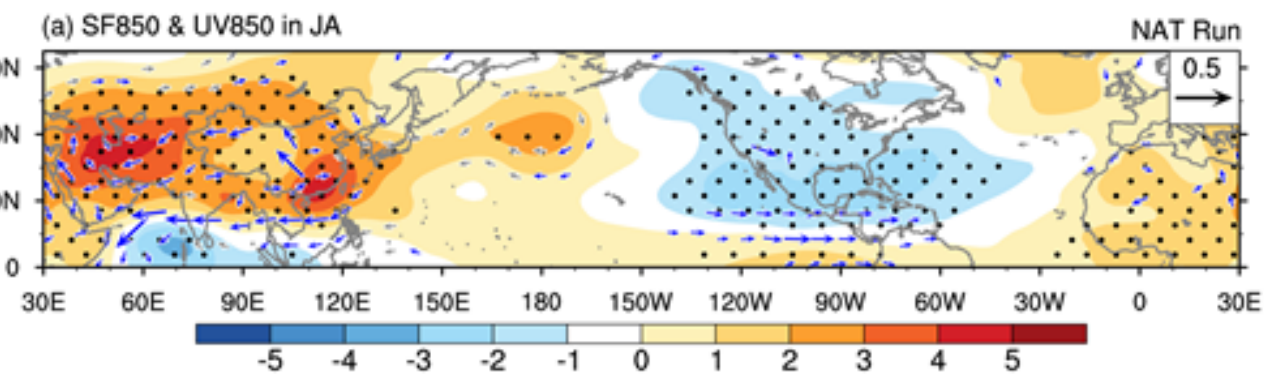

(b) VP200 in JA

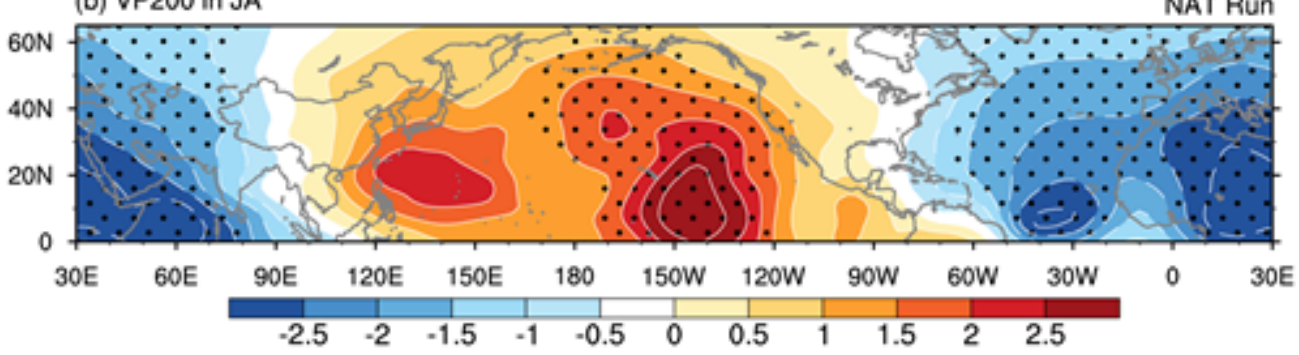

(c) PREC in JA

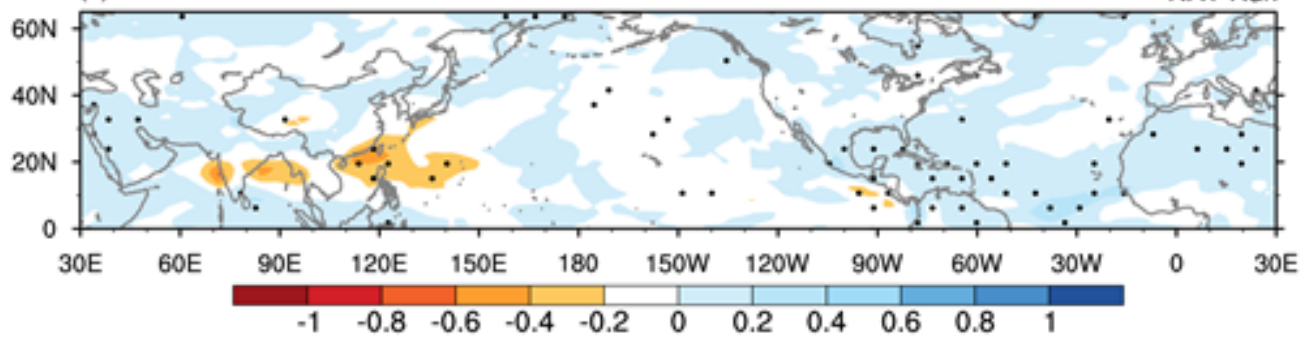

\section{Figure 10}

Same as Figs. 9b-d, but for the ensemble-mean difference between the NAT and control runs (former minus latter). 


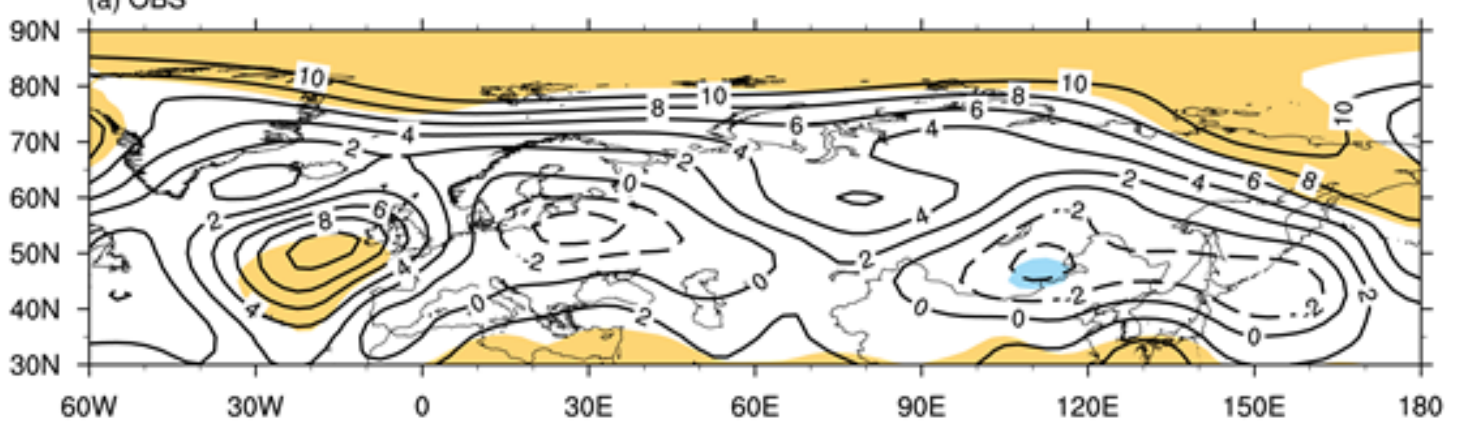

(b) SIM

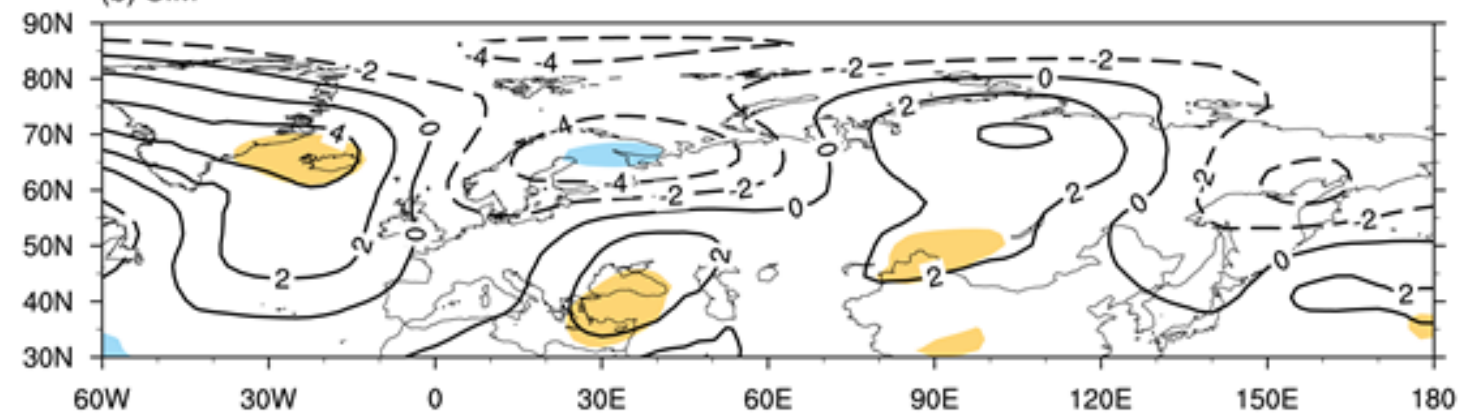

\section{Figure 11}

a Regressions of the 500-hPa geopotential height anomalies (unit: gpm) in JA against the NATI during the period of 1963-2002. Shading indicates significance at the $95 \%$ confidence level. b Same as in a, but for the ensemble-mean difference between the NAT and control runs (former minus latter).

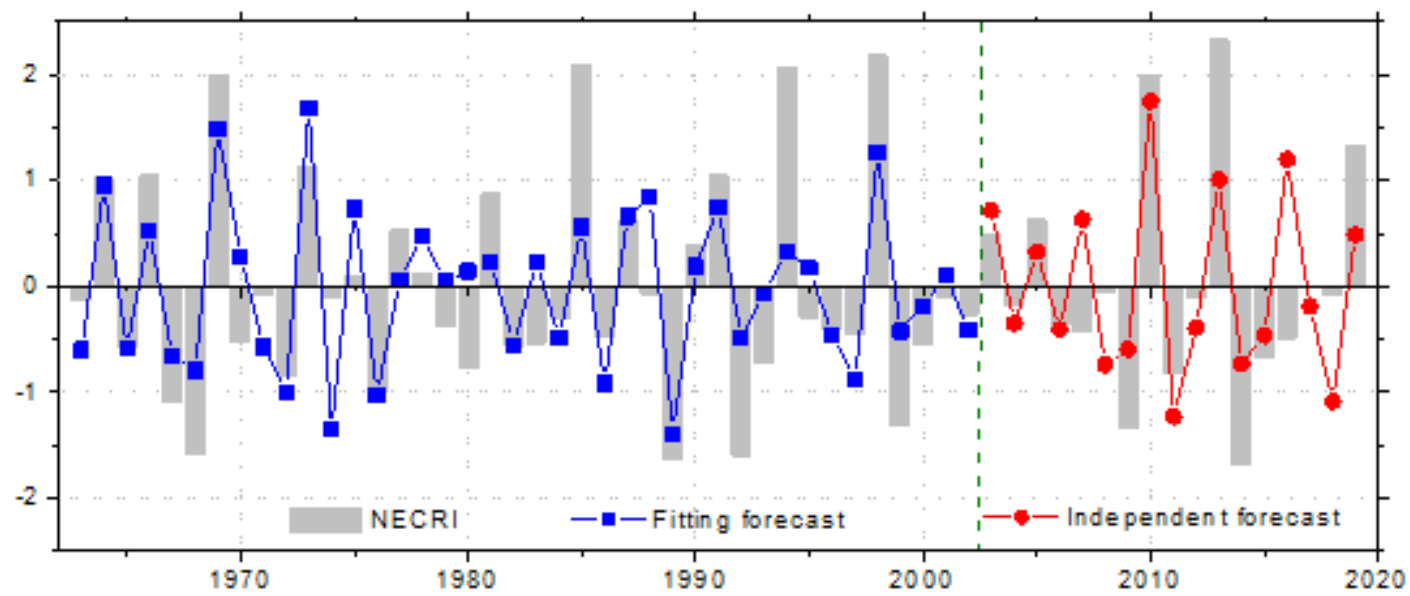

Figure 12

Time series of NECRI obtained from observation (histogram), fitting forecast (blue line) and independent forecast (red line) 